\title{
Growth factors in synaptic function
}

\author{
Vivian Y. Poon ${ }^{1}$, Sojoong Choi ${ }^{2}$ and Mikyoung Park ${ }^{2,3 *}$ \\ ${ }^{1}$ Neuroscience and Behavioral Disorders Program, Duke-NUS Graduate Medical School, Singapore, Singapore \\ ${ }^{2}$ WCl, Center for Functional Connectomics, Brain Science Institute, Korea Institute of Science and Technology, Seoul, South Korea \\ ${ }^{3}$ Department of Neuroscience, University of Science and Technology, Daejeon, South Korea
}

\section{Edited by:}

Akira Yoshii, Massachusetts Institute of Technology, USA

\section{Reviewed by:}

Isabel Perez-Otano, Centro de Investigacion en Medicina Aplicada,

Spain

Joachim H. R. Lübke, Research

Centre Jülich $\mathrm{GmbH}$, Germany

\section{*Correspondence:}

Mikyoung Park, Center for

Functional Connectomics, Brain

Science Institute, Korea Institute of

Science and Technology,

L7/Hwarangno 14-gil 5, Seoul

136-791, South Korea

e-mail:mikyoungpark7@gmail.com;

mpark@kist.re.kr
Synapses are increasingly recognized as key structures that malfunction in disorders like schizophrenia, mental retardation, and neurodegenerative diseases. The importance and complexity of the synapse has fuelled research into the molecular mechanisms underlying synaptogenesis, synaptic transmission, and plasticity. In this regard, neurotrophic factors such as netrin, Wnt, transforming growth factor- $\beta$ (TGF- $\beta$ ), tumor necrosis factor- $\alpha$ (TNF- $\alpha$ ), and others have gained prominence for their ability to regulate synaptic function. Several of these factors were first implicated in neuroprotection, neuronal growth, and axon guidance. However, their roles in synaptic development and function have become increasingly clear, and the downstream signaling pathways employed by these factors have begun to be elucidated. In this review, we will address the role of these factors and their downstream effectors in synaptic function in vivo and in cultured neurons.

Keywords: netrin, Wnt, TGF- $\beta$, TNF- $\alpha$, synaptogenesis, synaptic transmission and plasticity
Abbreviations: AA, arachidonic acid; ABI-1, Abl-interacting protein-1; Abl, Abelson tyrosine-protein kinase 1; AC, adenyl cyclase; AChR, acetylcholine receptor; ACR-, acetylcholine receptor; AD, Alzheimer's disease; ADAM17, a disintegrin and metallopeptidase domain 17; AMPAR, $\alpha$-amino-3-hydroxy-5methyl-4-isoxazolepropionic acid receptor; APC, adenomatous polyposis coli; $\mathrm{A} \beta$, amyloid- $\beta$; Babo, baboon; BMP, bone morphogenetic protein; BMPR, BMP receptor; CAM-, CAN cell migration defective; CaMKII, calcium/calmodulin-dependent protein kinase II; Cdc42, cell division cycle 42 ; CDK-5, cyclin-dependent kinase 5; CED-, cell death abnormality; CNS, central nervous system; CREB, cAMP response element-binding protein; CWN-, C. elegans WNT family; CYY-, cyclin Y; dactivin, Drosophila activin; Dad, daughters against decapentaplegic; Daw, dawdle; DBL-, decapentaplegic/BMP-like; DCC, deleted in colorectal cancer; DD, death domain; DFz2, Drosophila Frizzled-2; DGRIP, Drosophila glutamate receptor interacting protein; DOCK180, dedicator of cytokinesis 1; Drl, derailed; DSCAM, down syndrome cell adhesion molecule; DSH-, dishevelled related; Dvl, dishevelled; EJC, end-plate junctional current; Eps15, epidermal growth factor receptor pathway substrate 15; ERK, extracellular signal-regulated kinase; Evi/Wls/Srt, Evenness Interrupted/Wntless/Sprinter; FADD, fas-associated DD; FNI, frizzled nuclear import; $\mathrm{GABA}_{\mathrm{A}}, \gamma$-aminobutyric acid $\mathrm{A} ; \mathrm{GAP}$, guanosine triphosphatase-activating protein; Gbb, glass bottom boat; GEF, guanine nucleotide exchange factor; GluN2B, an NMDAR subunit; GSK3 $\beta$, glycogen synthase kinase $3 \beta$; HIV, human immunodeficiency virus; HFS, high frequency stimulation; HSPG, heparan sulfate proteoglycan; $\mathrm{IP}_{3}$, inositol-1,4,5-trisphosphate; JNK, c-Jun-amino-terminal kinase; LIMK1, LIM domain kinase 1; LIN-, abnormal cell lineage; LPS, lipopolysaccharide; LTD, long-term depression; LTP, long-term potentiation; Ly6, lymphocyte antigen 6; Mad, mothers against decapentaplegic; MAP, microtubule associated protein; MAPK, mitogen-activated protein kinase; Mav, maverick; MCPG, $\alpha$ methyl-4-carboxyphenylglycine; mEJC, miniature end-pate junctional current; mEPSC, miniature excitatory postsynaptic current; mGluR, metabotropic glutamate receptor; MIG-, abnormal cell migration; mIPSC, miniature inhibitory postsynaptic current; MPEP, 2-methyl-6-(phenylethynyl)pyridine; MuSK, musclespecific kinase; NF- $\mathrm{\kappa B}$, nuclear factor kappa B; NFAT, nuclear factor of activated T-cells; NGL, netrin G ligand; NMDAR, N-methyl-D-aspartate-type glutamate receptor; NMJ, neuromuscular junction; PCP, planar cell polarity; PCT-1, Pctaire kinase 1; PKA, protein kinase A; PKC, protein kinase C; PLC, phospholipase C; PPF, paired pulse facilitation; PSD-95, postsynaptic density protein 95; Rac1, rasrelated C3 botulinum toxin substrate 1; RIPK1, receptor-interacting protein kinase 1; ROR, receptor tyrosine kinase-like orphan receptor; Ryk, receptor-like tyrosine kinase; Sax, Saxophone; Smad, Mad homolog; Src, Rous sarcoma oncogene; TGF- $\beta$, transforming growth factor- $\beta$; Tkv, Thickveins; TNF- $\alpha$, tumor necrosis

\section{INTRODUCTION}

Human perception, learning, and memory are only possible when the nervous system is functioning normally. The primary building blocks of the nervous system are neurons-specialized cells that form connections, or synapses, with specific targets. Loss or malfunction of synapses leads to mental retardation, schizophrenia, and neurodegenerative diseases like Alzheimer's or Parkinson's disease.

As a functional synapse is a fundamental requirement for the brain to process any task, synaptic function is tightly regulated. This regulation occurs at multiple steps, such as recruitment and assembly of molecular machinery, synapse formation and stabilization, coordinated release of neurotransmitters, downstream signaling of receptors, maintenance, plasticity, and eventual loss of the synapse.

To study synaptic function, neurobiologists have utilized multiple model systems, including C. elegans, Drosophila, the vertebrate neuromuscular junction (NMJ), primary mammalian neurons, brain slice cultures, and rodent models. Pioneering work in invertebrates led to the identification of novel roles for growth factors in synaptic function (Zhang et al., 1997; Aberle et al., 2002; Chin et al., 2002; Marques et al., 2002; Packard et al., 2002; McCabe et al., 2003; Ziel and Sherwood, 2010), and subsequent studies have demonstrated similar synaptic functions for these growth factors in mammals (Krieglstein et al., 2011; Salinas, 2012; Horn et al., 2013).

factor- $\alpha$; TNFR, TNF receptor; TRADD, TNFR-associated DD protein; TRAF2, TNFR-associated factor-2; TRPV1, transient receptor potential subtype V1; UNC-, Uncoordinated; VDCC, voltage-dependent calcium channel; VTA, ventral tegmental area; Wg, Wingless; Wit, wishful thinking. 
Through these studies, the role of growth factors such as netrin, Wnt, transforming growth factor- $\beta$ (TGF- $\beta$ ), and tumor necrosis factor- $\alpha$ (TNF- $\alpha$ ) in synaptogenesis, synaptic transmission, and plasticity is gradually being elucidated. Netrin, Wnt, and TGF- $\beta$ both enhance and suppress synaptogenesis, and their effects are mediated through a variety of pathways (Shen and Cowan, 2010; Krieglstein et al., 2011; Koles and Budnik, 2012; Salinas, 2012). In addition, the netrin receptor Deleted in Colorectal Cancer (DCC) is implicated in synaptic plasticity (Horn et al., 2013) while members of the Wnt superfamily enhance synaptic function in vivo and in vitro primarily through the planar cell polarity (PCP) and calcium Wnt signaling pathways (Koles and Budnik, 2012; Salinas, 2012). In contrast, the TGF- $\beta$ superfamily and TNF- $\alpha$ enhance excitatory synaptic transmission, while suppressing inhibitory synaptic transmission (Krieglstein et al., 2011; Santello and Volterra, 2012). In this review, we will focus on the function of netrin, Wnt, TGF- $\beta$, and TNF- $\alpha$ in the various aspects of synaptic function and the downstream signaling pathways employed. Roles of other growth factors like brain-derived neurotrophic factor (BDNF), fibroblast growth factor (FGF), and glial cell line-derived neurotrophic factor (GDNF) are discussed elsewhere (Shen and Scheiffele, 2010; Wu et al., 2010; Duarte et al., 2012; Park and Poo, 2013).

\section{NETRIN}

The netrin family of laminin-related proteins is known for its critical role in axon guidance during neuronal development. Over the past two decades, netrins have been implicated in diverse processes in multiple tissues, including cell adhesion (Baker et al., 2006), cell survival (Ko et al., 2012), and tumorigenesis (Arakawa, 2004). Within the nervous system, there is emerging evidence for netrins as novel regulators of synaptogenesis and synaptic function (Shen and Cowan, 2010; Flores, 2011). As it is challenging to isolate a synaptogenic function of netrin that is independent of its function in guidance, the role for netrin at synapses has mostly been addressed in simple and genetically tractable systems like C. elegans, Drosophila, and Xenopus (Winberg et al., 1998; Colon-Ramos et al., 2007; Poon et al., 2008; Manitt et al., 2009). Nonetheless, as tools that allow temporal-specific perturbation of netrins or their signaling components become available (Lai Wing Sun et al., 2011; Horn et al., 2013), more studies addressing the synaptogenic role of netrin should follow.

The founding member of the netrin family, uncoordinated- 6 (UNC-6), was first identified as a component of the extracellular matrix that guides dorsoventral migration in C. elegans (Ishii et al., 1992). In mammals, the netrin family is composed of five members: netrin 1, 3 and 4, which are secreted and highly conserved, and netrin G1 and G2, which are glycophosphatidylinositol (GPI)-linked and vertebrate-specific. Netrin signaling is transduced through receptors such as DCC/Frazzled/UNC-40, neogenin, the UNC-5 family, and Down syndrome cell adhesion molecule (DSCAM) (Lai Wing Sun et al., 2011). The effectors that lie downstream of DCC, neogenin, and UNC-5 receptors comprise regulators of the cytoskeleton like the Rho family of GTPases, Src-family kinases, focal adhesion kinase and microtubule-associated proteins (Li et al., 2004b; Rajasekharan and Kennedy, 2009). In contrast, netrin Gs bind to netrin G ligands (NGLs) NGL-1/LRRC4C and NGL-2/LRRC4 (Nakashiba et al., 2000, 2002; Lin et al., 2003; Kim et al., 2006). The NGL family also includes NGL-3, a member that does not bind netrin Gs. As these membrane-anchored netrins and their ligands are less characterized, their signaling pathways remain unclear.

Though netrins and their receptors are widely studied for their role in nervous system development, they are continually expressed throughout adulthood (Livesey and Hunt, 1997; Manitt and Kennedy, 2002; Horn et al., 2013), suggesting that they play additional roles that are distinct from early developmental events. In addition, both netrin 1 and its receptor DCC are present in synaptosomes (Horn et al., 2013) and may thus act locally at synapses. Netrin Gs are similarly highly expressed in the adult brain and exhibit complex non-overlapping expression patterns (Nakashiba et al., 2002; Yin et al., 2002).

Netrin signaling in the nervous system is further altered when neuronal activity is perturbed. Levels of netrin receptors and netrin G2 are regulated by psychostimulant drugs (Yetnikoff et al., 2007; Argento et al., 2012), endocannabinoid receptor antagonists (Argaw et al., 2011), and epilepsy-induced activity (Pan et al., 2010). Amphetamine treatment elevates the expression of DCC and UNC-5 receptors in the mesocorticolimbic dopamine system in adult rats (Yetnikoff et al., 2007), while methylphenidate lowers the expression of DCC in the ventral tegmental area (VTA) of adult mice (Argento et al., 2012). It is intriguing to note that this down-regulation of DCC levels is associated with diminished sensitivity to cocaine (Argento et al., 2012). Taken together, these studies suggest that drugs that induce plasticity in the dopamine system regulate netrin receptor levels. Treatment of cultured primary cortical neurons with endocannabinoid receptor antagonists elevates surface expression of DCC (Argaw et al., 2011), suggesting that synaptic transmission of endocannabinoids regulates DCC activity. Netrin G2 levels are also elevated in the cortex of epileptic patients and mice (Pan et al., 2010), indicating that netrin G2 expression may be regulated by alterations in neuronal activity induced by epilepsy. While the significance, consequence, and underlying mechanisms of the regulation of netrin and its receptors are still being addressed, these studies provide preliminary evidence for a putative role for netrins in synaptic function. We will next explore the known functions of netrins in synaptogenesis, synaptic transmission, and plasticity.

\section{ROLE OF NETRINS IN SYNAPTOGENESIS}

Work in Drosophila motor neurons was the first to suggest a synaptogenic role for netrins. Overexpressing netrin in ventral muscles leads to DCC/frazzled-dependent formation of ectopic synapses in the transverse nerve in flies (Winberg et al., 1998). Similarly, addition of netrin into the Xenopus optic tectum augments the number of pre-synaptic sites in retinal ganglion cell axons in a DCC-dependent manner (Manitt et al., 2009). However, the downstream signaling components remain unknown.

Subsequent studies in C. elegans provided further evidence for the synaptogenic function of netrin (Figure 1A). Secretion of netrin/UNC- 6 by glia coordinates innervation between AIY and RIA, two interneurons that mediate thermotaxis (Colon-Ramos 

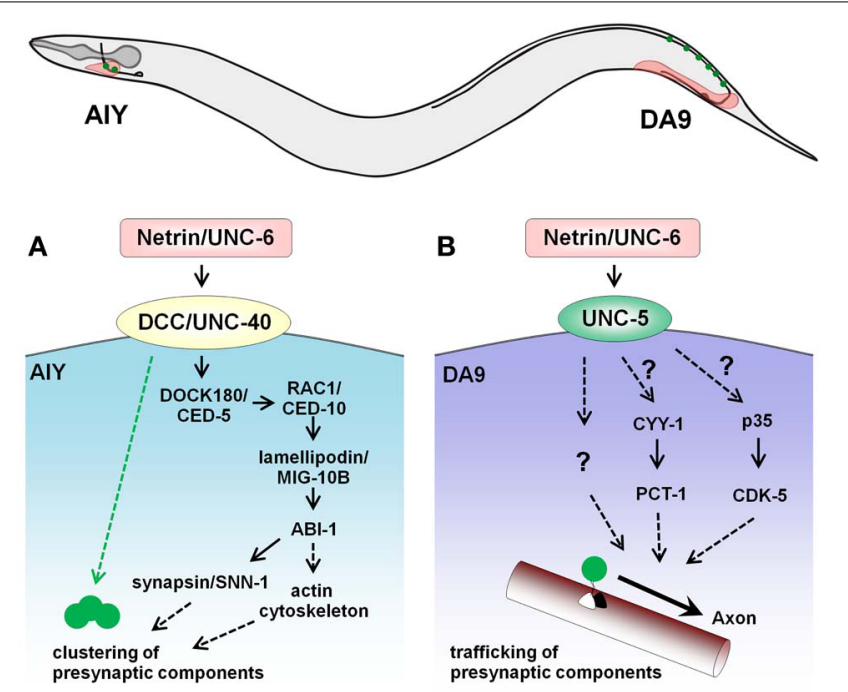

FIGURE 1 | Opposing roles of netrin/UNC -6 on synaptogenesis in the C. elegans AIY interneuron and DA9 motor neuron. (A) In the head region, glial sheath cells secrete UNC-6 and promote pre-synaptic assembly in AIY. UNC-6 signals through the DCC/UNC-40 receptor in AIY and recruits DOCK180/CED5 to pre-synaptic sites, leading to actin cytoskeleton remodeling and the pre-synaptic vesicle clustering. In addition, activation of UNC-40 clusters active zone proteins in a DOCK180/CED5-independent fashion (green dotted arrow). (B) In the tail, UNC-6 secreted by the ventral muscles acts through the UNC-5 receptor to prevent mislocalization of pre-synaptic components to the dendrite of the DA9 motor neuron. Pctaire kinase PCT-1, cyclin CYY-1, cyclin-dependent kinase CDK-5 and its activator p35 also regulate the kinesin/dynein-mediated localization of pre-synaptic components and may act downstream of UNC-6. The black arrow indicates the trafficking of components to the axon. in DA9 (Ou et al., 2010), it is possible that these factors lie downstream of netrin/UNC-6-UNC-5 signaling.

Apart from regulating pre-synapse formation, the netrin receptor DCC/UNC-40 also directs differentiation of muscles that are post-synaptic to motor axons and egg-laying motor neurons in C. elegans. Absence of this receptor leads to a reduction in post-synaptic muscle arm extensions (Alexander et al., 2009) and abolishes vulval muscle arms (Li et al., 2013a). In both instances, however, netrin/UNC-6 is not required. Taken together, the above studies demonstrate that netrin and its receptors modulate synaptogenesis in invertebrates and Xenopus. However, this begs the question: does netrin function similarly in mammals?

The role of netrin 1 and its receptor DCC in the mesocorticolimbic dopamine system has been explored (Flores, 2011). Adult mice lacking DCC have reduced dendritic spine densities in layer $\mathrm{V}$ pyramidal neurons in the medial prefrontal cortex (Grant et al., 2007; Manitt et al., 2011), suggesting that DCC is required for post-synaptic differentiation. These mice also exhibit defects in pubertal maturation of synaptic connectivity of dopaminergic neurons in this brain area, where numbers of tyrosine hydroxylase-positive varicosities are elevated (Manitt et al., 2011). Further work is needed to confirm if these varicosities are functional pre-synaptic terminals and if this is a secondary effect of axon misguidance. In addition, knocking down DCC in dopaminergic neurons in vitro suppresses the formation of autaptic axon terminals ( $\mathrm{Xu}$ et al., 2010), consistent with a pro-synaptogenic role for DCC. While studies in C. elegans have provided some insights into netrinmediated signaling pathways involved in regulating synaptogenesis, further studies in the mammalian central nervous system (CNS) are pertinent to elucidating the synaptogenic function of netrins.

Unlike secreted netrins, which act as both positive and negative regulators of synaptogenesis, the netrin G2 receptor NGL-2 primarily promotes synaptogenesis in cultured hippocampal neurons (Kim et al., 2006). NGL-2 was first identified as a novel binding partner of the post-synaptic scaffolding protein PSD95. Overexpressing NGL-2 elevates the number of dendritic spines while knocking it down causes a loss in excitatory, but not inhibitory synapses. In hippocampal slices, removing NGL-2 leads to selective loss of spines in CA1 dendrites in the stratum radiatum, and spine formation requires NGL-2-netrin G2 binding (Denardo et al., 2012). Intriguingly, netrin G2 knockout mice have no detectable anomalies in the density of PSD-95 clusters in the hippocampus (Nishimura-Akiyoshi et al., 2007). Work in cultured hippocampal neurons further indicates that NGL-2induced post-synaptic differentiation occurs via multiple mechanisms that are PSD-95-dependent or -independent (Kim et al., 2006). In addition to driving post-synaptic differentiation, NGL2 , like the post-synaptic cell adhesion molecule neuroligin, is sufficient to induce pre-synaptic differentiation (Kim et al., 2006). NGL-2 likely binds to netrin G2 and other factors to mediate this process since netrin G2 alone is insufficient to induce postsynaptic differentiation. Understanding the signaling pathways downstream of NGL-2 will be critical for comprehending the mechanisms of NGL-2 function. 


\section{ROLE OF NETRINS IN SYNAPTIC TRANSMISSION AND PLASTICITY}

Given that netrins and their signaling components are expressed in adulthood (Livesey and Hunt, 1997; Manitt and Kennedy, 2002; Horn et al., 2013) and regulate synaptogenesis (Winberg et al., 1998; Kim et al., 2006; Colon-Ramos et al., 2007; Poon et al., 2008; Manitt et al., 2009; Flores, 2011), one may expect netrins to regulate synaptic transmission and plasticity. Several groups employing DCC-deficient mice and mammalian hippocampal cultures have attempted to explore this possibility.

Mice lacking DCC have altered dopamine transmission and are insensitive to the stimulant drug of abuse amphetamine (Grant et al., 2007; Yetnikoff et al., 2007, 2010). These mice exhibit enhanced amphetamine-induced dopamine release in the medial prefrontal cortex, but display the opposite response in the nucleus accumbens (Grant et al., 2007). A reduction in DCC also suppresses the rewarding effects of amphetamine on behavior and neuronal activity (Grant et al., 2007), and this effect is likely due to loss of DCC activation in the VTA (Yetnikoff et al., 2010). A deficiency in DCC also abolishes the amphetamine-induced increase in the expression of dendritic spine-associated protein spinophilin in the VTA (Yetnikoff et al., 2010).

A recent study further implicates DCC in synaptic plasticity in forebrain pyramidal neurons in the adult (Horn et al., 2013). Forebrain neurons in which DCC is deleted late in development had shorter dendritic spines, impaired long-term potentiation (LTP) but not long-term depression (LTD), and diminished expression of $\mathrm{N}$-methyl-D-aspartate-type glutamate receptor (NMDAR) subunit GluN2B, Src, phosphorylated phospholipase $C \gamma 1$, and phosphorylated Src family kinase Fyn. As deficits in LTP displayed by the DCC knockout mouse are rescued by Src activation or NMDAR function enhancement, it is likely that DCC regulates NMDAR-dependent plasticity through Src (Horn et al., 2013).

Using heterozygous mutants or conditional knockout mice, the previous studies showed that DCC is required for plasticity in the limbic system and the hippocampus. What about the ligand? To examine if netrin 1 affects synaptic function and plasticity, Bayat and colleagues infused netrin 1 into the hippocampus of mice after cerebral ischemia (Bayat et al., 2012). This treatment improved spatial memory impairment, basal evoked potential, and LTP, suggesting that netrin 1 is sufficient to enhance synaptic transmission. However, the underlying mechanism was not determined and the effects observed may be secondary to a prosurvival function of netrin 1 . Nonetheless, this is the first study investigating an in vivo role for netrin in mammalian synaptic function and plasticity.

Apart from secreted netrins and their receptors, NGL-2 is also required for proper synaptic transmission. As previously described, NGL-2 drives synaptogenesis in cultured hippocampal neurons. Knocking down NGL-2 diminishes the frequency, but not the amplitude of miniature excitatory post-synaptic currents (mEPSCs) and has no effect on inhibitory currents (Kim et al., 2006). In hippocampal slices, removal of NGL-2 reduces synaptic transmission at Schaffer collateral synapses in the stratum radiatum of the CA1 region (Denardo et al., 2012). Hence, in addition to promoting synaptogenesis, NGL-2 drives synaptic transmission in distinct regions in the hippocampus, and regulates excitatory but not inhibitory synaptic function.

\section{Wnts}

First identified as key regulators of embryonic development, Wnt proteins have gained prominence over the past decade for their role in synapse formation and function in both the central and peripheral nervous system (Budnik and Salinas, 2011; Koles and Budnik, 2012; Salinas, 2012). These secreted lipo-glycoproteins are evolutionarily conserved and the mammalian genome comprises 19 Wnt genes (Willert and Nusse, 2012).

To achieve a wide spectrum of functions, Wnt proteins act through a diverse number of pathways-the canonical, divergent canonical, PCP, calcium Wnt signaling, and Frizzled nuclear import (FNI) pathways (Kuhl et al., 2000; Mlodzik, 2002; Ciani et al., 2004; Logan and Nusse, 2004; Speese and Budnik, 2007). These pathways lie downstream of the seven-pass transmembrane Frizzled receptors, and with the exception of the FNI pathway, activate the scaffolding protein Dishevelled (Dvl). In the canonical pathway, Dvl inhibits the Axin/Adenomatous Polyposis Coli (APC)/Glycogen synthase kinase $3 \beta$ (Gsk3 $\beta$ ) complex, and $\beta$ catenin is imported into the nucleus where it activates gene transcription. In the divergent pathway, inhibition of Gsk $3 \beta$ leads to decreased phosphorylation and augmented activity of microtubule-associated proteins. In the PCP pathway, Dvl regulates the cytoskeleton by activating the small Rho GTPases RhoA and Racl, and c-Jun-amino-terminal kinase (JNK). In the calcium Wnt signaling pathway, Dvl increases intracellular calcium levels, thus activating multiple targets, including calcium/calmodulin-dependent protein kinase II (CaMKII), protein kinase $\mathrm{C}(\mathrm{PKC})$, and calcineurin, which results in the nuclear import of nuclear factor of activated T-cells (NFAT). In the FNI pathway, Frizzled-2 is internalized, processed, and imported into the nucleus. Though less characterized, Wnts also signal through members of the receptor tyrosine kinase-like orphan receptor (ROR) and the tyrosine kinase-like receptor Derailed (Drl)/Ryk families. Two recent reviews describe the Wnt signaling pathways in further detail (Koles and Budnik, 2012; Mulligan and Cheyette, 2012).

Given their importance in neuronal development and function, it is not surprising to note that Wnt ligands and their signaling components are present in neurons and regulated by activity. Neuronal activity-mediated regulation of Wnt signaling is prevalent in systems ranging from the C. elegans and Drosophila NMJ to the vertebrate CNS. Neuronal stimulation leads to secretion of the C. elegans Wnt ligand CWN-2 (Jensen et al., 2012), as well as release of the Drosophila Wnt1 ligand Wingless (Wg) from synaptic boutons in the larval NMJ (Ataman et al., 2008) and the fly olfactory sensory neuron (Chiang et al., 2009). In a central serotonergic neuron in Drosophila, activity triggers Wnt signaling and leads to dendritic refinement (Singh et al., 2010). Similarly, during activity-dependent dendrite development in hippocampal neurons, activity elevates Wnt release (Yu and Malenka, 2003) and Wnt2 transcription (Wayman et al., 2006). Wnt3a is also released at synapses in the hippocampus during tetanic stimulation (Chen et al., 2006). Altering activity with exposure to different environments or learning paradigms also changes Wnt 
levels in the hippocampus. Wnt7a/b levels in post-synaptic CA3 neurons rise when mice are kept in an enriched environment (Gogolla et al., 2009); mice undergoing spatial learning in the Morris water maze have augmented levels of Wnt7, Wnt5, but not Wnt3. Lastly, levels of surface Frizzled-5, a receptor of Wnt7a in the hippocampus, increase with high frequency stimulation (HFS) in a Wnt-dependent fashion (Sahores et al., 2010). Taken together, the tight interplay between neuronal activity and Wnt signaling suggests a critical role for Wnts and their downstream effectors to modulate synaptogenesis, synaptic transmission, and plasticity.

\section{ROLE OF Wnts IN SYNAPTOGENESIS}

In the larval NMJ of Drosophila, members of the Wnt family promote formation of both pre- and post-synapses (Figure 2). Loss of Wg leads to defective pre- and post-synaptic specializations (Packard et al., 2002). During development, presynaptic vesicular release of the Wg-binding protein Evenness Interrupted/Wntless/Sprinter (Evi/Wls/Srt) leads to proper Wg secretion and recruitment of a Drosophila glutamate receptor interacting protein (dGRIP) to post-synaptic sites (Korkut

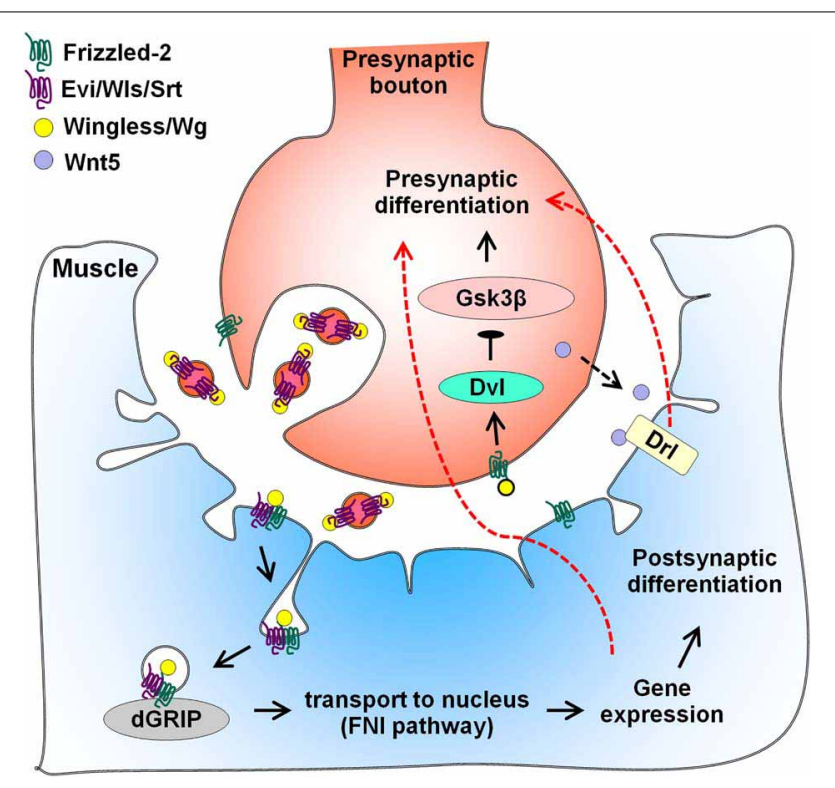

FIGURE 2 | Wnt regulation of larval NMJ differentiation. Vesicular release of the Wnt-binding protein Evenness Interrupted/Wntless/Sprinter (Evi/Wls/Srt) facilitates pre-synaptic secretion of Wingless/Wg. In the pre-synaptic bouton, binding of $\mathrm{Wg}$ to the Frizzled-2 receptor (DFz2) activates components of the canonical pathway and leads to pre-synaptic differentiation. In the post-synaptic muscle, Wg binds to DFz2, inducing endocytosis of the receptor. As part of the Frizzled nuclear import (FNI) pathway, Evi/WIs/Srt recruits the Wg receptor-interacting protein dGRIP, leading to transport of DFz2 to the nucleus. Entry of DFz2 into the nucleus alters gene expression, promoting post-synaptic, and possibly, pre-synaptic differentiation (red dotted arrow). Additional regulators of $\mathrm{Wg}$ signaling excluded from this figure include laminin A, integrin, the HSPG perlecan/trol and HSPG sulfation. In addition, Wnt5 is also secreted by the pre-synaptic bouton (black dotted arrow) and acts through the tyrosine kinase-like receptor Derailed (Drl) to promote pre-synaptic differentiation retrogradely (red dotted arrow). et al., 2009). Wg binds the Drosophila Frizzled-2 (DFz2) receptor that is located both in the motor neuron and muscle. Several studies indicate that divergent signaling pathways are employed both in the pre-synaptic motor neuron and in the post-synaptic muscle. In the case of the latter, DFz2 is endocytosed from the post-synaptic membrane and transported to the nucleus by binding dGRIP, and this process is required for assembly of the post-synapse (Mathew et al., 2005; Ataman et al., 2006, 2008; Speese et al., 2012). On the pre-synaptic side, Wg signaling involves components of the canonical pathway like Arrow/Low-density lipoprotein receptor-related protein Dvl and Shaggy/Gsk3 $\beta$ to regulate bouton number (Ataman et al., 2008; Miech et al., 2008). Anterograde Wg signaling also modulates NMJ growth through the retrograde signal laminin A and the pre-synaptic integrin pathway (Tsai et al., 2012). Thus, Wg signals bi-directionally and utilizes distinct pathways in preand post-synaptic compartments. Recently, Kamimura and colleagues found that bi-directional signaling by $\mathrm{Wg}$ is regulated by a secreted heparan sulfate proteoglycan (HSPG) perlecan/trol (Kamimura et al., 2013). Coincidentally, Wg levels are also altered by HSPG sulfation (Dani et al., 2012). In addition to Wg, loss of Wnt5 leads to a reduction in the number of pre-synaptic boutons and suppresses active zone formation (Liebl et al., 2008). Wnt5 signals through its post-synaptic receptor Drl but some of its functions are Drl-independent. Taken together, these studies suggest that $\mathrm{Wg}$ and $\mathrm{Wnt} 5$ drive synaptogenesis in the fly NMJ.

In the vertebrate NMJ, Wnt3 and Wnt11r enhance synaptogenesis. Wnt3 augments acetylcholine receptor (AChR) clustering in the chick wing NMJ and in cultured myotubes via the noncanonical PCP pathway involving Racl activation and Rho signaling (Rattner et al., 1997; Weston et al., 2003; Niehrs, 2006; Henriquez et al., 2008). Similarly, the non-conventional Wnt11r is required for $\mathrm{AChR}$ clustering in zebrafish, but acts through the muscle-specific kinase (MuSK)/unplugged receptor and Dvl1 (Jing et al., 2009). In addition to Wnt3 and Wnt11r, Wnt signaling components like Dvl1, Dvl1-interacting protein p21-activated kinase1 (Luo et al., 2002), APC (Wang et al., 2003), and $\beta$-catenin (Zhang et al., 2007; Li et al., 2008) are implicated as positive regulators of NMJ development.

Studies in the glutamatergic cerebellar glomerular rosette, a multi-synaptic structure formed between mossy fibers and granule cells, provided the first glimpse into the synaptogenic role of Wnts in the vertebrate CNS. Loss of Wnt7a or Dvll delays the maturation of glomerular rosettes and leads to defects in the localization of pre-synaptic markers while expression of Wnt7a in granule cells induces clustering of the pre-synaptic protein synapsin I in mossy fiber axons (Hall et al., 2000; Ahmad-Annuar et al., 2006). Wnt7a similarly stimulates clustering of pre-synaptic markers in hippocampal neurons and acts through the Frizzled-5 receptor (Cerpa et al., 2008; Sahores et al., 2010). In addition to regulating the pre-synapse, Wnt7a signaling also promotes dendritic spine growth and PSD-95 clustering through Dvl1 and CaMKII (Ciani et al., 2011). Lastly, mice exposed to an enriched environment have an increased number of synapses in their hippocampus and this effect is dependent on Wnt7a/b (Gogolla et al., 2009). 
Apart from Wnt7a/b, Wnt5a also regulates synaptogenesis in the hippocampus. There are conflicting reports on the effect of Wnt5a on the pre-synapse while the role of Wnt5a at the postsynapse is less controversial. Several studies report that Wnt5a increases clustering of pre-synaptic proteins and synaptic contacts (Varela-Nallar et al., 2012), and acts through ROR1/2 receptors to promote pre-synaptic assembly in cultured hippocampal neurons (Paganoni et al., 2010). However, other studies indicate that Wnt5a decreases the number of pre-synaptic terminals or has no effect on hippocampal neurons (Davis et al., 2008; Farias et al., 2009). In dendrites, Wnt5a increases calcium levels, spine size, and spine number during development (Varela-Nallar et al., 2010), and clusters PSD-95 through a JNK-dependent signaling pathway (Farias et al., 2009). On top of regulating synapse formation in the pre- and post-synaptic compartments of excitatory synapses, Wnt5a also augments the insertion and clustering of $\gamma$ aminobutyric acid $\mathrm{A}\left(\mathrm{GABA}_{\mathrm{A}}\right)$ receptors in hippocampal neurons by activating CaMKII (Cuitino et al., 2010).

Like Wnt7 and Wnt5a, Wnt3 also induces pre-synaptic protein clustering in hippocampal neurons and drives synapse formation between sensory and motor neurons in the spinal cord. Through the pre-synaptic Frizzled-1 receptor, Wnt3a elevates the number of Bassoon clusters in axons (Varela-Nallar et al., 2009). In motor neurons, Wnt3 secretion induces synapsin clustering and regulates terminal arborization of sensory neurons in a Gsk3 $\beta$ dependent manner (Krylova et al., 2002). Hence, Wnts, particularly Wnt7a/b, Wnt5a, and Wnt3, regulate synaptogenesis in vertebrate cerebellar, hippocampal, and spinal neurons through diverse signaling mechanisms. Whereas Wnt7a signals through Frizzled-5, Dvl1, and/or CaMKII, Wnt5a signaling occurs via ROR receptors, JNK, or CaMKII, and Wnt3 acts through Gsk3 $\beta$.

While the previously described Wnt ligands are generally positive regulators of synaptogenesis, other Wnt ligands in Drosophila, C. elegans, and mice also negatively regulate synaptogenesis. Wnt4 is preferentially expressed in the Drosophila muscle cell M13. Absence of Wnt4, its receptor DFz2, Drl2, or Dvl results in the formation of ectopic synapses by motor neuron 12 onto M13 (Inaki et al., 2007). Similarly, in the C. elegans cholinergic motor neuron DA9, LIN-44, a Wnt ligand secreted by the tail hypodermal cells, inhibits ectopic synapse formation in the posterior segment of the neuron through the LIN-17/Frizzled receptor and DSH-1/Dvl (Klassen and Shen, 2007). Since other known canonical, PCP, calcium Wnt signaling pathway effectors have no effect, a pathway comprising novel mediators may be employed. In vertebrates, Wnt3a inhibits post-synapse formation by reducing AChR clustering in cultured myotubes through the canonical pathway involving $\beta$-catenin (Wang et al., 2008). Taken together, Wnts both enhance and suppress synaptogenesis through the engagement of both canonical and non-canonical pathways (Table 1).

\section{ROLE OF Wnts IN SYNAPTIC TRANSMISSION AND PLASTICITY}

Just as the fly NMJ provided important insights into how Wnts regulate synapse formation, further studies utilizing this model system have yielded additional roles for Wnt5 and Wnt1/Wg in synaptic transmission and plasticity. Absence of Wnt5, but not
Drl, lowers the amplitude of evoked end-plate junctional currents (EJCs) and lowers the frequency of miniature EJCs (mEJCs), indicating defects in pre-synaptic transmission (Liebl et al., 2008). The $w g$ mutant also has suppressed activity-dependent synaptic growth (Ataman et al., 2008). In addition, Wg is a potential negative regulator of homeostatic compensation, where it is inhibited by the paired box protein Pax3/7 homolog gooseberry (Marie et al., 2010). However, the downstream mechanisms remain elusive.

A recent study on the $C$. elegans Wnt CWN-2 at the NMJ provides some mechanistic insight (Jensen et al., 2012). In contrast to another Wnt ligand LIN-44 that inhibits pre-synapse formation, $\mathrm{CWN}-2$ promotes synaptic strength by regulating the translocation of an AChR ACR-16/ $\alpha 7$ to the synapse (Jensen et al., 2012). Reduction in AChR enrichment and synaptic current is observed both in the absence of CWN-2 in the motor neuron and during the loss of LIN-17/Frizzled, ROR receptor tyrosine kinase CAM-1 or DSH-1/Dvl in muscles. Other Frizzled receptors and Ryk/Drl are not required for the elevation in post-synaptic strength induced by CWN-2. The identities of the effectors downstream of DSH-1/Dvl responsible for AChR translocation remain to be elucidated.

In addition to the synaptogenic functions of Wnt7a, Wnt5a, and Wnt3a, these ligands also increase synaptic transmission in cerebellar and hippocampal slices. In the mossy fiber-granule cell synapses of Wnt7a/Dvl1 double mutant mice, neurotransmitter release is diminished (Ahmad-Annuar et al., 2006). Wnt7a and post-synaptic Dvl1 also increase the frequency of mEPSCs, indicating larger neurotransmitter release in CA3-CA1 synapses in the hippocampus (Cerpa et al., 2008; Ciani et al., 2011). Ciani and colleagues further observed a CaMKII-dependent increase in the amplitude of mEPSCs in hippocampal neurons induced by Wnt7a, suggesting that this ligand acts through the calcium Wnt pathway in dendrites to augment synaptic strength (Ciani et al., 2011). On the other hand, Wnt5a increases both excitatory and inhibitory synaptic transmission and signals through the PCP and calcium Wnt signaling pathways in hippocampal neurons. Wnt5a and JNK, a component of the PCP pathway, regulate glutamatergic synaptic transmission (Farias et al., 2009). In addition, Wnt5a facilitates LTP by augmenting the proportion of GluN2B-containing NMDARs at the synapse, as well as the amplitude of NMDAR currents through the elevation of calcium and the activation of CaMKII (Varela-Nallar et al., 2010; Cerpa et al., 2011). In contrast, through the same calcium Wnt signaling pathway, Wnt5a also increases $\mathrm{GABA}_{\mathrm{A}}$ receptor recycling and miniature inhibitory post-synaptic currents (mIPSCs) (Cuitino et al., 2010). Wnt3a is likely to have a similar effect as Wnt5a since blocking its activity decreases LTP in hippocampal slices (Chen et al., 2006). Consistent with the previous finding, Wnt3a enlarges neurotransmitter release through pre-synaptic Frizzled-1 in hippocampal neurons (Varela-Nallar et al., 2009) and enhances excitatory transmission in hippocampal slices (Beaumont et al., 2007).

The studies mentioned above suggest that Wnts increase synaptic function in vivo and in vitro through the PCP pathway, calcium Wnt signaling, and possibly other pathways (Table 1). However, do Wnts affect neural circuit function? In the 
Table 1 | Known functions of Wnts in synaptogenesis and synaptic function.

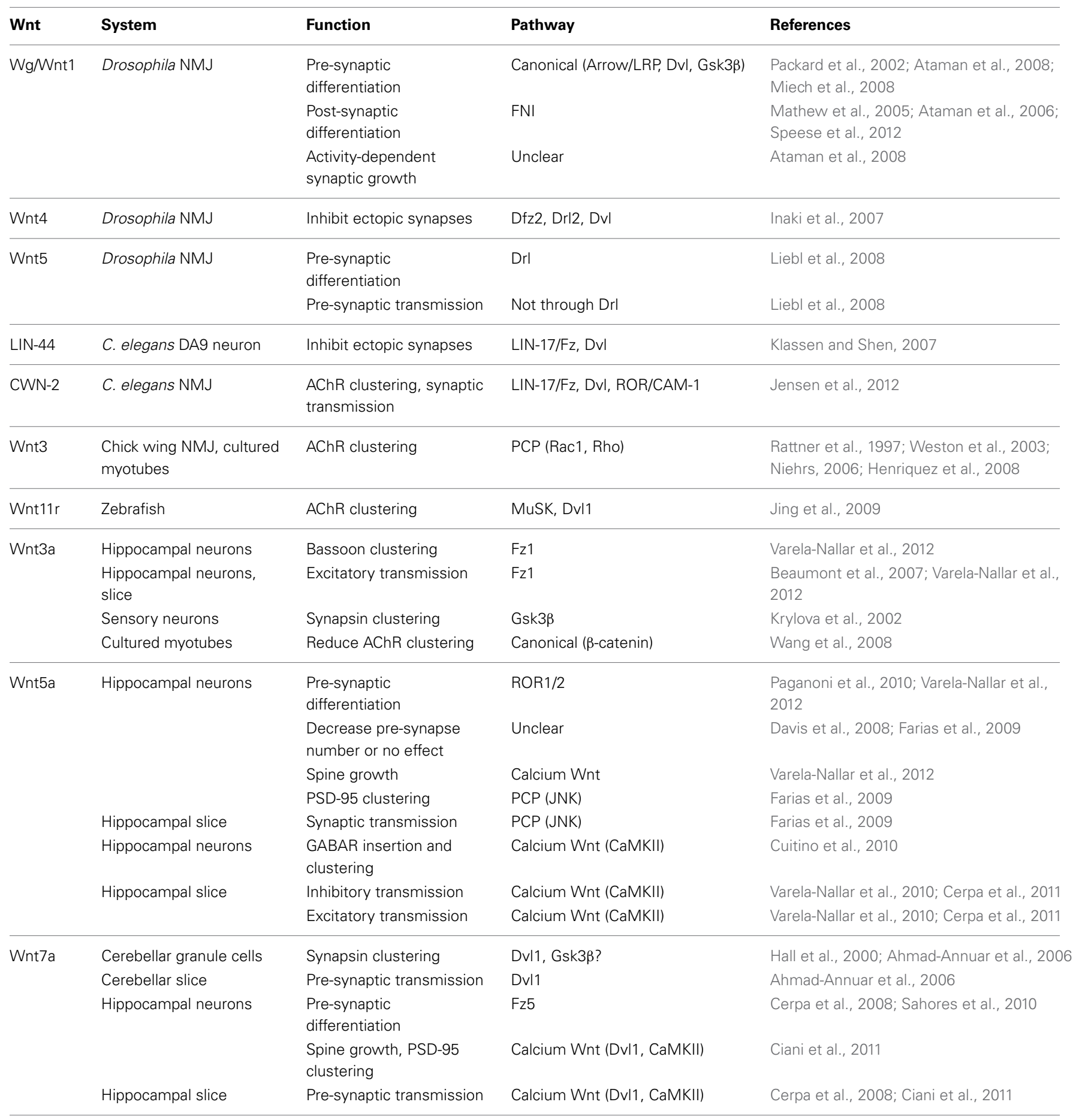

developing Xenopus optic tectum, Lim and colleagues reported that Wnt secreted from tectal cells enhances visual experiencedependent plasticity of receptive fields of cells in the dorsal tectum (Lim et al., 2010). This suggests that regulation of synapse formation and function by Wnt signaling likely leads to downstream effects on circuit function.

\section{TRANSFORMING GROWTH FACTOR- $\beta$}

TGF- $\beta$ signaling is critical for multiple biological processes, including proliferation, development, patterning, and regeneration (Kubiczkova et al., 2012). The TGF- $\beta$ superfamily consists of more than 30 secreted members in humans that are broadly classified into two ligand subfamilies: the TGF- $\beta$-activin-Nodal 
group and the bone morphogenetic proteins (BMPs) group (Shi and Massague, 2003). Different members signal through distinct subtypes of heterotetrameric receptor complexes composed of specific type I and II receptors, leading to phosphorylation of R-Smads and inducing their binding to Smad4. Upon entering the nucleus, the Smad complex interacts with transcription factors to enhance gene expression. Massague provides a detailed description of TGF- $\beta$ signaling in two recent reviews (Massague, 2012a,b).

Multiple members of the TGF- $\beta$ superfamily play a role in the developing nervous system and several are regulated by neuronal activity. For instance, developmental expression of TGF- $\beta$ in the mammalian neocortex is required for axon initiation in vivo and in vitro (Yi et al., 2010). Depolarization of primary hippocampal neurons with high levels of potassium or glutamate leads to the release of TGF- $\beta$ (Specht et al., 2003) and the elevated expression of TGF- $\beta 2$ and TGF- $\beta 3$ (Lacmann et al., 2007). In addition, both kainate-induced seizures and HFS augment levels of activin $\beta A$ mRNA in the hippocampus (Andreasson and Worley, 1995; Inokuchi et al., 1996) while sensory deafferentation of the visual cortex reduces activin $\beta \mathrm{A}$ mRNA levels in cortical neurons in specific layers (Andreasson and Worley, 1995). It was also recently reported that lowering activity in the C. elegans AVA command interneuron by exposure to pathogenic bacteria enhances release of TGF- $\beta / \mathrm{DBL}-1$ (Zhang and Zhang, 2012). This precise regulation of TGF- $\beta$ and activin levels by synaptic input suggests an activity-dependent function for these TGF- $\beta$ family members in synaptogenesis, synaptic transmission, and plasticity.

\section{ROLE OF TGF- $\beta$ IN SYNAPTOGENESIS}

Studies in the Drosophila NMJ have provided key mechanistic insights into how TGF- $\beta$ family members act as positive regulators of synaptogenesis (Figure 3). Multiple reports from the early 2000s have demonstrated that the BMP homolog Glass Bottom Boat (Gbb) secreted by muscle cells signals through pre-synaptic receptors wishful thinking (Wit), thickveins (Tkv) and saxophone (Sax) to promote NMJ synapse formation (Aberle et al., 2002; Marques et al., 2002; McCabe et al., 2003; Rawson et al., 2003). Gbb binding both activates the LIM-domain kinase LIMK1 to stabilize the synapse (Eaton and Davis, 2005) and phosphorylates the R-Smad transcription factor Mothers against decapentaplegic (Mad) to increase the number of synapses (Rawson et al., 2003). Several downstream targets have been identified, including the Rac guanine nucleotide exchange factor (GEF) Trio (Ball et al., 2010; Kim and Marques, 2010). This signaling requires dyneinmediated retrograde axonal transport of BMP receptors (Smith et al., 2012b). The Tkv receptor and Mad transcription factor are also present in the muscle and may affect post-synaptic development and function (Dudu et al., 2006). To prevent synaptic overgrowth, this pathway is negatively regulated by several factors in the motor neuron, including the cysteine-rich transmembrane $\mathrm{BMP}$ regulator 1 homolog that antagonizes BMP signaling (James and Broihier, 2011), the inhibitory Smad Daughters against decapentaplegic (Dad) and the E3 ubiquitin ligase Highwire (McCabe et al., 2004). In addition, the Cdc42 pathway inhibits post-synaptic Gbb secretion (Nahm et al., 2010a,b) while endocytic and endosomal machinery lower surface levels of BMP

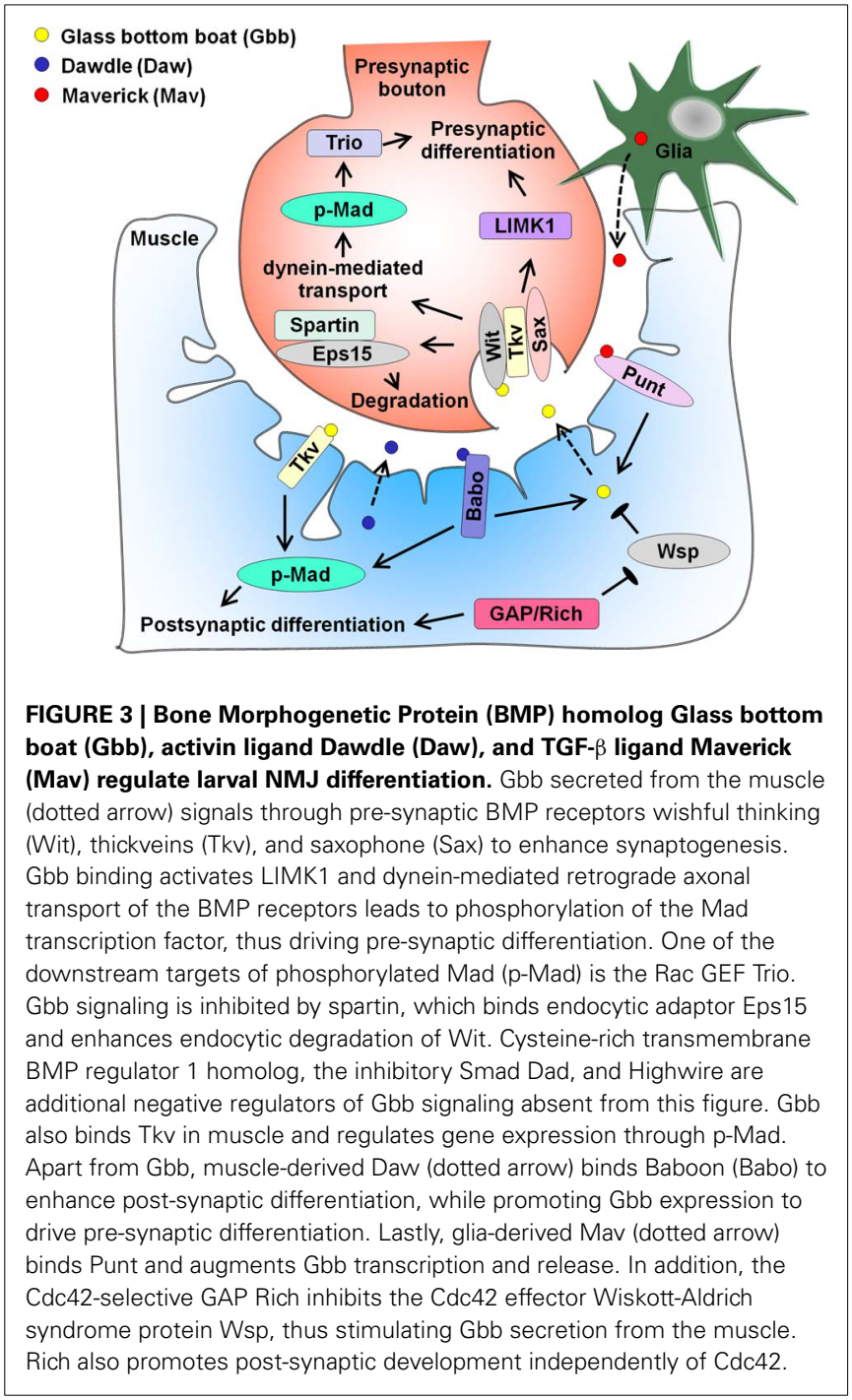

receptors in neurons (Sweeney and Davis, 2002; Wang et al., 2007; O'Connor-Giles et al., 2008). Gbb secretion is further modulated by HSPG sulfation (Dani et al., 2012). Spartin, which binds to endocytic adaptor Eps15 was recently found to inhibit synaptic growth at the NMJ by promoting endocytic degradation of BMP receptor Wit (Nahm et al., 2013). This leads to elevated levels of fragile $\mathrm{X}$ mental retardation protein, a translational repressor of Futsch/microtubule associated protein MAP1B mRNA. Apart from Gbb, the activin ligand Dawdle (Daw) and the TGF- $\beta$ ligand Maverick (Mav) are also present at the NMJ. Daw acts through the post-synaptic activin type I receptor Baboon (Babo) and Smad2 transcription factor to promote synaptogenesis at the NMJ (Ellis et al., 2010). Daw and Babo further regulate pre-synaptic differentiation by regulating Gbb expression (Ellis et al., 2010). Secreted by glia, Mav regulates synaptic growth by binding muscle activin-type receptor Punt and by increasing Gbb signaling (Fuentes-Medel et al., 2012). Taken together, the BMP homolog Gbb and the activin ligand Daw are potent activators of synapse growth at the NMJ and achieve this by promoting gene expression through the Smad transcription factors. The TGF- $\beta$ ligand 
Mav, the activin ligand Daw, and a host of other intracellular components regulate Gbb signaling to ensure strict control of synaptogenesis at the NMJ.

TGF- $\beta$ family members also enhance synapse formation in mammalian neurons in vitro. Treating primary neurons with TGF- $\beta 1$, activin, or BMP7 augments synapse formation through different effectors. TGF- $\beta 1$ secreted from astrocytes increases synaptogenesis in cortical neurons by inducing secretion of Dserine, the co-agonist of the NMDAR (Diniz et al., 2012). Activin promotes synaptic development and alters spine morphology in hippocampal neurons by modulating actin dynamics. This process is independent of protein and RNA synthesis (ShojiKasai et al., 2007). BMP7 accelerates hippocampal dendrite development and elevates the rate of synaptogenesis, but the underlying mechanism remains unclear (Withers et al., 2000). Though these findings indicate a synaptogenic role for TGF- $\beta 1$, activin, and BMP7, it is uncertain if these TGF- $\beta$ family members function likewise in vivo in the vertebrate CNS. Recently, Xiao and colleagues examined the auditory system of conditional BMPR1a and BMPR1b double knockout mice and observed smaller synapses with fewer docked synaptic vesicles, as well as multiple inputs, at the calyx of Held (Xiao et al., 2013). Hence, BMP signaling regulates synapse size and elimination in vivo at the calyx of Held.

While other TGF- $\beta$ family members have primary roles in driving synaptogenesis, Drosophila activin (dactivin) and myoglianin, a Drosophila TGF- $\beta 2$ ligand, are involved in synaptic patterning in the visual system and NMJ, respectively (Ting et al., 2007; Awasaki et al., 2011; Yu et al., 2013). In the Drosophila visual system, mutations in Babo and the Smad2-interacting nuclear import protein importin- $\alpha 3$ lead to overlap of R7 photoreceptor axon terminals with those in neighboring columns (Ting et al., 2007). Similar defects in tiling occur in the absence of dactivin or Smad2. Hence, activin regulates activity of Smad2 to ensure formation of appropriate pre-synaptic contacts. In the larval NMJ, TGF- $\beta 2 /$ myoglianin secreted from muscle acts through Babo to prevent formation of ectopic synapses and this process is regulated by the immunoglobulin superfamily transmembrane protein Plum, as well as the ecdysone receptor-B1 (Yu et al., 2013). However, the downstream signaling mechanism has not been characterized.

\section{ROLE OF TGF- $\beta$ IN SYNAPTIC TRANSMISSION AND PLASTICITY}

In addition to driving synaptogenesis, members of the TGF- $\beta$ family are implicated in promoting excitatory synaptic transmission. Work on long-term synaptic facilitation in the marine mollusk Aplysia californica provided the earliest evidence of the ability of TGF- $\beta 1$ to sculpt synaptic transmission (Zhang et al., 1997). This was followed by the finding that TGF- $\beta 1$ induces long-term increases in neuronal excitability by activating mitogen-activated protein kinase (MAPK), a well-established regulator of LTP in Aplysia (Chin et al., 2006). TGF- $\beta 1$ also acutely activates MAPK, altering distribution of the pre-synaptic protein synapsin and reducing synaptic depression in the Aplysia sensorimotor synapse (Chin et al., 2002). Treatment of cultured hippocampal neurons with TGF- $\beta 2$ also led to an analogous effect-decreased short-term synaptic depression of evoked post-synaptic currents (Fukushima et al., 2007). This observation is associated with heightened phosphorylation of cAMP response element-binding protein (CREB). Consistent with a role for TGF- $\beta 2$ in promoting synaptic transmission, TGF- $\beta 2$ knockout mice have impaired transmission in GABAergic/glycinergic and glutamatergic synapses in the brainstem where both frequency of mEPSCs and total charge transfer are suppressed (Heupel et al., 2008). This effect on pre-synaptic transmission by TGF$\beta 1$ and TGF- $\beta 2$ is reminiscent of diminished neurotransmitter release in the fly NMJ when BMP signaling is disrupted, and this process is likely partially mediated through the lymphocyte antigen 6 (Ly6) neurotoxin-like molecule target of Wit (Aberle et al., 2002; Marques et al., 2002; Baines, 2004; McCabe et al., 2004; Nahm et al., 2010b; Kim and Marques, 2012). Conversely, chordin null mice that have elevated BMP signaling exhibit augmented pre-synaptic neurotransmitter release, as reflected from enhanced paired pulse facilitation (PPF) and LTP (Sun et al., 2007). This observation is unlikely due to transduction through Smad4 since Smad4 knockout mice have stronger, instead of weaker, PPF in excitatory synaptic transmission in the hippocampus (Sun et al., 2010). In addition, at the calyx of Held synapse, knocking out both BMPR1a and BMPR1b reduced the amplitude of EPSCs and lengthened decay times, indicating that a loss in BMP signaling reduces synaptic transmission (Xiao et al., 2013).

Besides TGF- $\beta 1$, TGF- $\beta 2$, and BMP, activin also enhances excitatory synaptic transmission. In cultured hippocampal neurons, activin phosphorylates NMDARs, possibly inducing LTP (Kurisaki et al., 2008). This signaling occurs through Src family tyrosine kinases, PDZ proteins, and activin receptor interacting protein 1 . Coherent with this finding, transgenic mice with impaired activin function have reduced NMDA currents and LTP in glutamatergic synapses in the hippocampus (Muller et al., 2006). Similarly, inhibiting activin by overexpressing follistatin in mouse forebrain neurons also impairs hippocampal late-LTP and long-term memory formation during contextual fear conditioning (Ageta et al., 2010). What are the downstream mediators that induce LTP in the presence of BMP and activin? As Smad4deficient mice do not exhibit defects in LTP or spatial memory, it is possible that BMP and activin regulate hippocampal LTP through non-canonical signaling pathways that might include MAPK (Zhou et al., 2003; Sun et al., 2010).

Activin also suppresses inhibitory synaptic transmission, but this may occur through the canonical Smad-dependent pathway (Krieglstein et al., 2011). Impairing activin function by expressing a dominant-negative mutant of activin receptor in forebrain neurons enhanced spontaneous GABA release and $\mathrm{GABA}_{B}$ receptor function in hippocampal neurons and suppressed anxiety-like behavior in mice (Zheng et al., 2009). Since Smad4 knockout mice have larger paired-pulse depression of $\mathrm{GABA}_{\mathrm{A}}$ currents in the hippocampus (Sun et al., 2010), it is possible that activin regulates GABAergic synapses through Smad4. Lastly, activin indirectly affects the excitatory-inhibitory balance by decreasing the number of GABAergic interneurons while increasing that of dentate gyrus granule cells (Sekiguchi et al., 2009). Taken together, the TGF- $\beta$ superfamily enhances excitatory synaptic transmission, while suppressing inhibitory synaptic transmission. The 
downstream effectors differ for the different members and likely involve both Smad-dependent and Smad-independent pathways. Several other reviews cover further details on the effect of TGF- $\beta$ on synapses and behavior (Krieglstein et al., 2011; Salinas, 2012).

\section{TUMOR NECROSIS FACTOR- $\alpha$}

TNF- $\alpha$ is a type II transmembrane $26 \mathrm{kDa}$ precursor molecule which is proteolytically cleaved by the metalloprotease TNF- $\alpha$ converting enzyme, a disintegrin and metallopeptidase domain 17 (ADAM17) to generate a soluble $17 \mathrm{kDa}$ homotrimeric proinflammatory cytokine (Horiuchi et al., 2010). Both membranebound and soluble forms of TNF- $\alpha$ contribute to a broad range of physiological and pathological activities, including cell proliferation, differentiation, apoptosis, and inflammatory responses in various cells (Wang et al., 2005; Chapard et al., 2012).

TNF- $\alpha$ is secreted by a variety of cells such as macrophages, monocytes, neutrophils, T cells, natural killer cells, adipocytes, and fibroblasts (Fahey et al., 1995; Jovinge et al., 1996; Cawthorn and Sethi, 2008; Ambler et al., 2012; Brotas et al., 2012; Zakka et al., 2012), and its signaling is transduced through TNF receptor 1 (TNFR1) and TNF receptor 2 (TNFR2). Soluble TNF- $\alpha$ binds preferentially to TNFR1, which is expressed in neurons (Brambilla et al., 2011) whereas transmembrane TNF- $\alpha$ binds to TNFR2, which is mainly expressed in immune cells such as those of the myeloid lineage, lymphocytes, and macrophages (McCoy and Tansey, 2008).

TNFRs regulate both cell death and survival depending on the cellular environment and context. Activation of TNFR1 recruits the intracellular death domain (DD)-containing adaptor TNFR-associated DD protein (TRADD), which can also recruit the receptor-interacting protein kinase 1 (RIPK1) and TNFR-associated factor-2 (TRAF2). This complex leads to the activation of the transcription factor AP-1 through MAPK and JNK pathways that prevent the triggering of cell death processes. In contrast, TRADD can also promote the recruitment of the Fas-associated DD protein (FADD), which is associated with a caspase-dependent or caspase-independent cell death signaling process known as apoptosis or necrosis, respectively (Chu, 2013). These cell death processes require the internalization of the TNFR (Schneider-Brachert et al., 2004).

Numerous studies have recently shown that TNF- $\alpha$ is involved in inflammatory events in the CNS and have opposing effects depending on their levels in the brain (Hoffmann et al., 2009; Mc Guire et al., 2011; Smith et al., 2012a). TNF- $\alpha$ is secreted by non-neural cells in the brain, including activated astrocytes and microglial cells (Santello and Volterra, 2012) in response to pathological brain conditions and diseases, which can play a protective role in neurons. Under physiological conditions, TNF$\alpha$ controls the inflammatory response, hence defending against infection. However, excessive amounts of TNF- $\alpha$ are indicative of acute and chronic neuroinflammation. Not surprisingly, TNF- $\alpha$ is involved in several neurodegenerative disorders associated with neuroinflammation and neuronal cell death such as Alzheimer's disease (AD), Parkinson's disease, and HIV-associated dementia (Brabers and Nottet, 2006; Frankola et al., 2011). Consistent with these reports, chronic expression of neuronal TNF- $\alpha$ enhances neuronal cell death in an AD mouse model (Janelsins et al., 2008).
Since the effect of TNF- $\alpha$ signaling is largely dependent on its concentration, multiple factors including neuronal activity, excitotoxicity, and neuroinflammation are involved in TNF- $\alpha$ regulation. Elevating neuronal activity by whisker stimulation elevates TNF- $\alpha$ expression in the somatosensory cortex, as measured by immunostaining (Churchill et al., 2008). Excitotoxicity induced by chronic treatment of NMDA also enhances the expression of TNF- $\alpha$ and other neuroinflammatory markers (Chang et al., 2008). Lastly, treatment with lipopolysaccharide (LPS) augments the expression of TNF- $\alpha$ (Ikeda et al., 2007; Dholakiya and Benzeroual, 2011; Welser-Alves and Milner, 2013). TNF- $\alpha$ released from microglia and astrocytes up-regulates gene transcription for arachidonic acid (AA) cascade enzymes via the nuclear factor kappa B (NF-кB) pathway, which has been shown to damage neurons by activating pro-apoptotic factors and caspase-3 (Rao et al., 2012).

During neuroinflammation, an elevation in TNF- $\alpha$ levels and AA signaling alters synaptic protein expression and leads to the loss of synapses (Figure 4A). LPS-induced neuroinflammation lowers the protein levels of several key molecules including the pre-synaptic vesicle protein synaptophysin, the neuronspecific post-synaptic F-actin-binding protein drebin, and PSD95 (Kellom et al., 2012; Rao et al., 2012). Reductions in these pre- and post-synaptic proteins suggest that high TNF- $\alpha$ levels induced by neuroinflammation may enhance synaptic loss. Furthermore, synaptic loss induced by LPS is abolished in neurons cultured with microglia that produce less TNF- $\alpha$, indicating that TNF- $\alpha$ mediates LPS-induced synapse loss (Xing et al., 2011; Kellom et al., 2012).

\section{ROLE OF TNF- $\alpha$ IN SYNAPTIC TRANSMISSION AND PLASTICITY}

TNF- $\alpha$ has been reported to play important roles in neuronal functions such as microglia activation, synaptic transmission, and synaptic plasticity (Stellwagen et al., 2005; Watters and O'Connor, 2011). Activated astrocytes and microglia increase the expression and secretion of TNF- $\alpha$ (Santello and Volterra, 2012), and also promote glutamatergic excitatory synaptic transmission and plasticity (Stellwagen and Malenka, 2006; Kawasaki et al., 2008; Wheeler et al., 2009; Steinmetz and Turrigiano, 2010; Park et al., 2011a; Zhang and Dougherty, 2011; Zhang et al., 2011; O'Connor, 2013).

TNF- $\alpha$ was shown to regulate calcium currents at the postsynapse through the NF- $\kappa \mathrm{B}$ pathway (Furukawa and Mattson, 1998), as well as block LTP in the hippocampus (Butler et al., 2004; Pickering et al., 2005) (Figure 4A). In cultured hippocampal neurons, long-term but not short-term treatment with TNF- $\alpha$ augments calcium currents through post-synaptic L-type voltagedependent calcium channels (VDCCs), and decreases glutamate receptor agonist-induced currents. In addition, TNF- $\alpha$ blocks the early phase of LTP but not the late phase through the activation of TNFR1 and metabotropic glutamate receptors (mGluRs) in a p38 MAPK-dependent manner (Butler et al., 2004; Pickering et al., 2005). TNF- $\alpha$ activation of mGluRs leads to inositol1,4,5-trisphosphate $\left(\mathrm{IP}_{3}\right)$ receptor-mediated calcium release via phospholipase C (PLC), which elevates intracellular calcium concentration to impair LTP (Pickering et al., 2005). Group I/II mGluR antagonist MCPG and the selective mGluR5 antagonist 

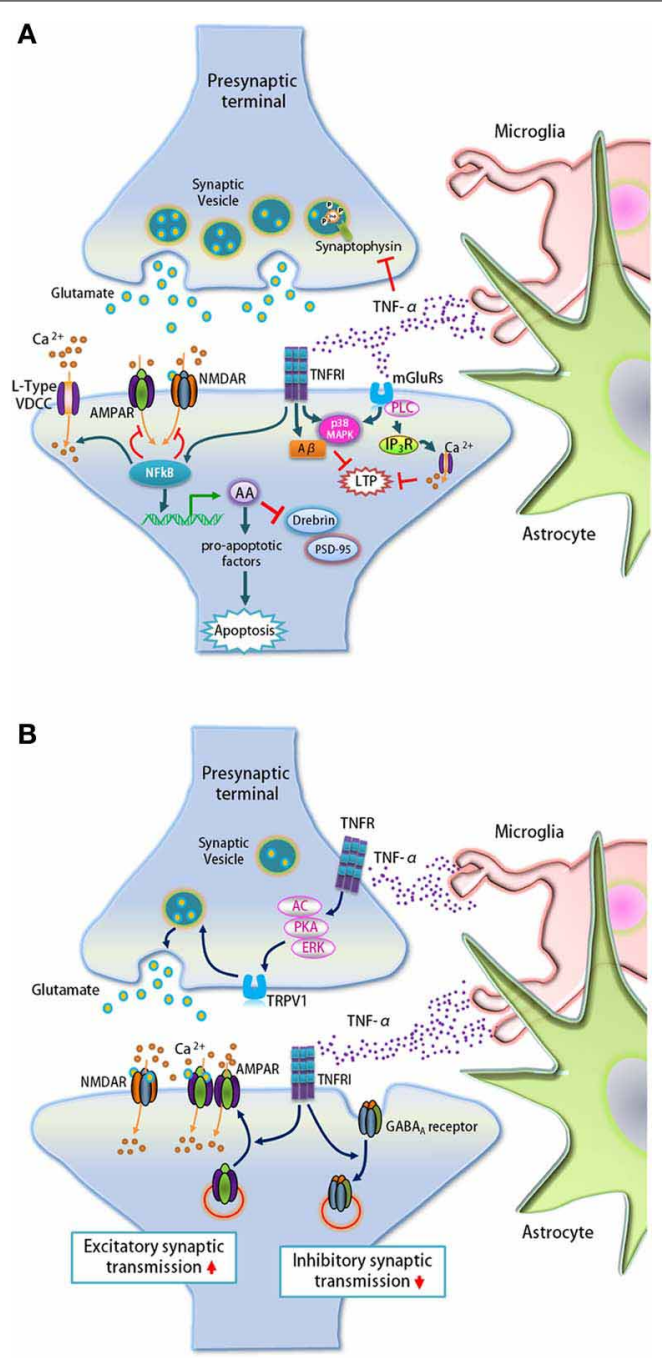

FIGURE 4 | TNF- $\alpha$ regulates synaptic loss, synaptic transmission, and plasticity. (A) TNF- $\alpha$ secreted by microglia and astrocytes up-regulates arachidonic acid (AA) via the NF-кB pathway that leads to synaptic loss by activating pro-apoptotic factors. The elevated AA signaling also down-regulates the expression of post-synaptic proteins drebrin and PSD-95, and pre-synaptic protein synaptophysin. In addition, TNF- $\alpha$ regulates intracellular calcium levels through the NF-KB pathway by regulating calcium entry through VDCCs, while suppressing glutamate receptor agonist-induced currents in hippocampal neurons. Lastly, TNF- $\alpha$ blocks the early phase of LTP through the activation of TNFR1 and mGluRs and this process is dependent on $\mathrm{p} 38 \mathrm{MAPK}, \mathrm{IP}_{3}$ receptor-mediated calcium release via PLC and A $\beta$. (B) Glia-derived TNF- $\alpha$ signals through preand post-synaptic TNFR1 to regulate pre-synaptic neurotransmitter release and the surface expression of AMPARs and GABAA receptors, respectively. In spinal cord outer lamina II neurons, TNF- $\alpha$ increases spontaneous EPSC frequency via TRPV1-mediated glutamate release that is mediated by $A C$, PKA, and ERK pathways from pre-synaptic terminals. At the post-synapse, TNF- $\alpha$ promotes GluA2-lacking AMPAR trafficking to the surface and induces $\mathrm{GABA}_{\mathrm{A}}$ receptor endocytosis.

MPEP significantly attenuate the inhibition of LTP by TNF- $\alpha$ (Cumiskey et al., 2007). The inhibition of LTP by TNF- $\alpha$ was significantly reversed by ryanodine, which blocks the release of intracellular calcium from ryanodine-sensitive stores. This implicates the involvement of ryanodine-sensitive intracellular calcium stores in TNF- $\alpha$-mediated inhibition of LTP (Cumiskey et al., 2007).

Apart from impairing LTP by regulating calcium stores, TNF$\alpha$ is also involved in LTP inhibition mediated by amyloid- $\beta$ (A $\beta)$, a major component of plaques in $\mathrm{AD}$ brains (Figure 4A). Many studies have shown that hippocampal LTP is blocked by A $\beta$ (Cullen et al., 1997; Lambert et al., 1998; Itoh et al., 1999; Chen et al., 2000; Stephan et al., 2001; Vitolo et al., 2002; Walsh et al., 2002; Raymond et al., 2003; Wang et al., 2005; Kotilinek et al., 2008; Jo et al., 2011; Li et al., 2011; Kimura et al., 2012; Olsen and Sheng, 2012; Li et al., 2013b). In addition, expression of TNF- $\alpha$ and its receptor TNFR1 is up-regulated in the brain and plasma of AD patients (Tarkowski, 2002; Li et al., 2004a). Using mutant mice null for TNFR1 and TNF- $\alpha$, as well as inhibitors, Wang and colleagues reported that TNF- $\alpha$ and TNFR1 are required for A $\beta$ mediated LTP inhibition. This TNF- $\alpha$-mediated inhibition of LTP is dependent on the activation of p38 MAPK and mGluR5 (Wang et al., 2005).

While the earlier studies focused on how pathological levels of TNF- $\alpha$ impair LTP in the hippocampus, the role of TNF- $\alpha$ in the spinal cord has also been explored. In several models of neuropathic pain, expression of TNF- $\alpha$ and TNFR1 is up-regulated in the spinal dorsal horn (Ikeda et al., 2007; Wei et al., 2007), and elevated levels of TNF- $\alpha$ induce spinal LTP in a JNK-, p38 MAPK-, and NF-кB-dependent fashion (Liu et al., 2007). Inhibition of TNF- $\alpha$ signaling abolishes LTP (Zhong et al., 2010), and intriguingly, inhibition of Src-family kinases leads to HFS-induced LTD, instead of LTP, and this inhibitory effect on spinal LTP is reversed by TNF- $\alpha$ addition (Zhong et al., 2010).

In addition to its effect on synaptic proteins, calcium levels, and LTP, TNF- $\alpha$ also enhances excitatory synaptic transmission and suppresses inhibitory synaptic transmission by regulating the surface expression of post-synaptic receptors (Figure 4B). Immunocytochemistry and electrophysiology revealed that treatment with TNF- $\alpha$ or astrocyte-derived conditioned media containing TNF- $\alpha$ elevates the surface levels of $\alpha$-amino-3-hydroxy5-methyl-4-isoxazolepropionic acid receptors (AMPARs) as well as the frequency of mEPSCs in cultured hippocampal neurons (Beattie et al., 2002). Glial TNF- $\alpha$ signaling through TNFR1 was shown to be involved in this AMPAR-mediated control of synaptic strength (Beattie et al., 2002). Furthermore, genetic approaches have shown that deletion of TNFR1 but not TNFR2 lowers the surface expression and synaptic localization of AMPARs, suggesting a critical role of TNFR1 signaling in AMPAR-mediated synaptic functions (He et al., 2012). Intriguingly, the effect of TNF- $\alpha$ on surface AMPARs preferentially affects GluA2-lacking AMPARs (Stellwagen et al., 2005). In contrast to its effect on AMPARs, TNF- $\alpha$ induces $\mathrm{GABA}_{\mathrm{A}}$ receptor endocytosis, diminishing surface expression of $\mathrm{GABA}_{\mathrm{A}}$ receptors and inhibitory synaptic strength (Stellwagen et al., 2005). Taken together, TNF- $\alpha$ affects both excitatory and inhibitory synaptic transmission, suggesting an important role of TNF- $\alpha$ in the homeostasis of neural circuits.

In addition, TNF- $\alpha$ also enhances synaptic transmission in the spinal cord. In spinal cord outer lamina II neurons, TNF- $\alpha$ increases spontaneous EPSC frequency but not amplitude via 
pre-synaptic transient receptor potential subtype V1 (TRPV1)mediated glutamate release that is dependent on adenylyl cyclase (AC), PKA, and the extracellular signal-regulated kinase (ERK) in pre-synaptic terminals (Park et al., 2011a). However, this spinal cord LTP induction is abolished in Tnfr1 $1^{-/}$mice, Tnfr2 $2^{-/-}$ mice, and Trpv1 $1^{-/-}$mice. This observation indicates the importance of TNFR and TRPV1 in spinal cord LTP (Park et al., 2011a).

\section{PERSPECTIVES}

Growth factors like netrin, Wnt, TGF- $\beta$, and TNF- $\alpha$ were first identified for their roles in axon guidance, embryonic development, cell proliferation, and inflammation, respectively. Over the past decade, they have gained prominence as regulators of the synapse. Similar to other patterning molecules such as sonic hedgehog (Salie et al., 2005), these growth factors play multiple roles during development. By utilizing effectors that multitask, the nervous system can carry out multiple functions more efficiently. For a single factor that has to fulfill various roles, diverse regulatory and signaling pathways that are spatiotemporally restricted must be put in place for it to achieve distinct functional outcomes.

Synapse formation largely involves transport, recruitment, and assembly of molecular machinery, cytoskeletal remodeling, and eventual stabilization of the synapse. As described earlier, netrin, Wnt, TGF- $\beta$, and TNF- $\alpha$ largely promote synaptogenesis and/or synaptic transmission but several including netrin/UNC6, Wnt5a, Wnt4, Wnt3a, Wnt/LIN-44, TGF- $\beta 2$, and activin also act as negative regulators. It is intriguing to note how some of these factors have opposing effects on synaptogenesis. In the case of netrin, the use of distinct receptors-DCC/UNC-40 or UNC5 determine its effect on the synapse (Colon-Ramos et al., 2007; Poon et al., 2008). For the Wnt family, only a few members have inhibitory effects on synaptogenesis and distinct pathways are utilized for this purpose (Table 1). Lastly, only two members of the TGF- $\beta$ family negatively regulate synaptogenesis: dactivin and myoglianin in Drosophila (Ting et al., 2007; Yu et al., 2013). As a pro-synaptogenic role for both these ligands has yet to be identified, they may activate pathways to specifically inhibit ectopic synapse formation. In addition, a putative mechanism coordinating synapse formation and elimination within a single neuron is discussed in a recent paper by Park and colleagues (Park et al., 2011b).

\section{REFERENCES}

Aberle, H., Haghighi, A. P., Fetter, R. D., McCabe, B. D., Magalhaes, T. R., and Goodman, C. S. (2002). Wishful thinking encodes a BMP type II receptor that regulates synaptic growth in Drosophila. Neuron 33, 545-558. doi: 10.1016/S08966273(02)00589-5

Ageta, H., Ikegami, S., Miura, M., Masuda, M., Migishima, R., Hino, T., et al. (2010). Activin plays a key role in the maintenance of longterm memory and late-LTP. Learn.

Apart from the opposing effects of several growth factors on synaptogenesis, TNF- $\alpha$ also appears to have conflicting effects on LTP and surface levels of AMPARs. Many studies have reported that an increased level of TNF- $\alpha$ impairs LTP in the hippocampus (Butler et al., 2004; Cumiskey et al., 2007; Liu et al., 2007, 2012) and also elevates the surface level of GluA2-lacking $\mathrm{Ca}^{2+}$ permeable AMPARs in cultured hippocampal neurons (Beattie et al., 2002; Stellwagen et al., 2005). It is important, however, to note that TNF- $\alpha$ increases the insertion of $\mathrm{Ca}^{2+}$-permeable AMPARs to both synaptic and extrasynaptic sites (Ferguson et al., 2008; Leonoudakis et al., 2008). In addition, $\mathrm{Ca}^{2+}$-permeable AMPARs are incorporated into the surface during LTP (Plant et al., 2006). Thus, one plausible mechanism is that TNF- $\alpha$ elevates the surface level of AMPARs at both synaptic and extrasynaptic sites, leading to excessive calcium influx through synaptic and extrasynaptic AMPARs, hence impairing LTP.

Considering how the synapse is key to proper communication between neurons, one would expect a complex interplay of multiple molecular mechanisms to ensure tight regulation of synaptic function. Studies in the C. elegans AIY interneuron and the Drosophila NMJ have provided strong mechanistic insights into how netrin, Wnt, and TGF- $\beta$ regulate synaptic function. However, it remains unclear if these growth factors utilize similar pathways in mammals. Identification of the target genes that lie downstream of the different signaling pathways will elucidate how the diverse growth factors differentially regulate synaptic function.

Given that synaptic function is compromised in a majority of neurological diseases, further understanding of the signaling pathways of netrin, Wnt, TGF- $\beta$, and TNF- $\alpha$ may contribute to novel therapeutic approaches for these debilitating disorders.

\section{ACKNOWLEDGMENTS}

We thank Bradley Baker and Jason Yi for critical review of the manuscript. The work in M. Park laboratory was supported by the World Class Institute (WCI) Program of the National Research Foundation of Korea (NRF) funded by the Ministry of Science, ICT \& Future Planning (MSIP) (NRF Grant Number: WCI 2009-003) and by the KIST Institutional Program (Project No. 2E24210). Vivian Y. Poon was supported by the Lee Kuan Yew Postdoctoral Fellowship and Ministry of Education Academic Research Fund, Singapore.

extension in Caenorhabditis elegans. Development 136, 911-922. doi: 10.1242/dev.030759

Ambler, D. R., Fletcher, N. M., Diamond, M. P., and Saed, G. M. (2012). Effects of hypoxia on the expression of inflammatory markers IL-6 and TNF-a in human normal peritoneal and adhesion fibroblasts. Syst. Biol. Reprod Med. 58, 324-329. doi: 10.3109/19396368.2012.713439

Andreasson, K., and Worley, P. F. (1995). Induction of beta-A activin expression by synaptic activity and during neocortical development. Neuroscience 69, 781-796. doi: 10.1016/0306-4522 (95)00245-E

Arakawa, H. (2004). Netrin-1 and its receptors in tumorigenesis. Nat. Rev. Cancer 4, 978-987. doi: 10.1038/nrc1504

Argaw, A., Duff, G., Zabouri, N., Cecyre, B., Chaine, N., Cherif, H., et al. (2011). Concerted action of CB1 cannabinoid receptor and deleted in colorectal cancer in axon guidance. J. Neurosci. 31, 1489-1499. doi: 10.1523/JNEUROSCI.4134-09.2011 
Argento, J. K., Arvanitogiannis, A., and Flores, C. (2012). Juvenile exposure to methylphenidate reduces cocaine reward and alters netrin1 receptor expression in adulthood. Behav. Brain Res. 229, 202-207. doi: 10.1016/j.bbr.2012.01.008

Ataman, B., Ashley, J., Gorczyca, D., Gorczyca, M., Mathew, D., Wichmann, C., et al. (2006). Nuclear trafficking of Drosophila Frizzled-2 during synapse development requires the PDZ protein dGRIP. Proc. Natl. Acad. Sci. U.S.A. 103, 7841-7846. doi: 10.1073/pnas.0600387103

Ataman, B., Ashley, J., Gorczyca, M., Ramachandran, P., Fouquet, W., Sigrist, S. J., et al. (2008). Rapid activity-dependent modifications in synaptic structure and function require bidirectional $\mathrm{Wnt}$ signaling. Neuron 57, 705-718. doi: 10.1016/j.neuron.2008.01.026

Awasaki, T., Huang, Y., O'Connor, M. B., and Lee, T. (2011). Glia instruct developmental neuronal remodeling through TGF-beta signaling. Nat. Neurosci. 14, 821-823. doi: $10.1038 / \mathrm{nn} .2833$

Baines, R. A. (2004). Synaptic strengthening mediated by bone morphogenetic proteindependent retrograde signaling in the Drosophila, C. N. S. J. Neurosci. 24, 6904-6911. doi: 10.1523/JNEUROSCI.1978-04.2004

Baker, K. A., Moore, S. W., Jarjour, A. A., and Kennedy, T. E. (2006). When a diffusible axon guidance cue stops diffusing: roles for netrins in adhesion and morphogenesis. Curr. Opin. Neurobiol. 16, 529-534. doi: 10.1016/j.conb.2006.08.002

Ball, R. W., Warren-Paquin, M., Tsurudome, K., Liao, E. H., Elazzouzi, F., Cavanagh, C., et al. (2010). Retrograde BMP signaling controls synaptic growth at the NMJ by regulating trio expression in motor neurons. Neuron 66, 536-549. doi: 10.1016/j.neuron.2010.04.011

Bayat, M., Baluchnejadmojarad, T., Roghani, M., Goshadrou, F., Ronaghi, A., and Mehdizadeh, M. (2012). Netrin-1 improves spatial memory and synaptic plasticity impairment following global ischemia in the rat. Brain Res. 1452, 185-194. doi: 10.1016/j.brainres.2012.03.008

Beattie, E. C., Stellwagen, D., Morishita, W., Bresnahan, J. C., Ha, B. K., Von Zastrow, M., et al. (2002). Control of synaptic strength by glial TNFalpha. Science 295, 2282-2285. doi: 10.1126/science. 1067859
Beaumont, V., Thompson, S. A., Choudhry, F., Nuthall, H., Glantschnig, H., Lipfert, L., et al. (2007). Evidence for an enhancement of excitatory transmission in adult CNS by Wnt signaling pathway modulation. Mol. Cell. Neurosci. 35, 513-524. doi: 10.1016/j.mcn.2007.03.004

Brabers, N. A., and Nottet, H. S. (2006). Role of the pro-inflammatory cytokines TNF-alpha and IL-1beta in HIV-associated dementia. Eur. J. Clin. Invest. 36, 447-458. doi: 10.1111/j.1365-2362.2006.01657.x

Brambilla, R., Ashbaugh, J. J., Magliozzi, R., Dellarole, A., Karmally, S., Szymkowski, D. E., et al. (2011). Inhibition of soluble tumour necrosis factor is therapeutic in experimental autoimmune encephalomyelitis and promotes axon preservation and remyelination. Brain 134, 2736-2754. doi: 10.1093/brain/awr199

Brotas, A. M., Cunha, J. M., Lago, E. H., Machado, C. C., and Carneiro, S. C. (2012). Tumor necrosis factor-alpha and the cytokine network in psoriasis. An. Bras. Dermatol. 87, 673-681. Quiz 682-673. doi: 10.1590/S036505962012000500001

Budnik, V., and Salinas, P. C. (2011). Wnt signaling during synaptic development and plasticity. Curr. Opin. Neurobiol. 21, 151-159. doi: 10.1016/j.conb.2010.12.002

Butler, M. P., O'Connor, J. J., and Moynagh, P. N. (2004). Dissection of tumor-necrosis factor-alpha inhibition of long-term potentiation (LTP) reveals a p38 mitogen-activated protein kinasedependent mechanism which maps to early-but not latephase LTP. Neuroscience 124, 319-326. doi: 10.1016/j. neuroscience.2003.11.040

Cawthorn, W. P., and Sethi, J. K. (2008). TNF-alpha and adipocyte biology. FEBS Lett. 582, 117-131. doi: 10.1016/j.febslet.2007.11.051

Cerpa, W., Gambrill, A., Inestrosa, N. C., and Barria, A. (2011). Regulation of NMDA-receptor synaptic transmission by Wnt signaling. J. Neurosci. 31, 9466-9471. doi: 10.1523/JNEUROSCI.631110.2011

Cerpa, W., Godoy, J. A., Alfaro, I., Farias, G. G., Metcalfe, M J., Fuentealba, R., et al. (2008). Wnt-7a modulates the synaptic vesicle cycle and synaptic transmission in hippocampal neurons. J. Biol. Chem. 283, 5918-5927. doi: 10.1074/jbc.M705943200

Chang, Y. C., Kim, H. W., Rapoport, S. I., and Rao, J. S. (2008).
Chronic NMDA administration increases neuroinflammatory markers in rat frontal cortex cross-talk between excitotoxicity and neuroinflammation. Neurochem. Res. 33, 2318-2323. doi: 10.1007/s11064-008-9731-8

Chapard, C., Hohl, D., and Huber M. (2012). The role of the TRAFinteracting protein in proliferation and differentiation. Exp. Dermatol. 21, 321-326. doi: 10.1111/j.16000625.2012.01477.x

Chen, G., Chen, K. S., Knox, J., Inglis, J., Bernard, A., Martin, S. J., et al. (2000). A learning deficit related to age and beta-amyloid plaques in a mouse model of Alzheimer's disease. Nature 408, 975-979. doi $10.1038 / 35046031$

Chen, J., Park, C. S., and Tang, S. J. (2006). Activity-dependent synaptic Wnt release regulates hippocampal long term potentiation. J. Biol. Chem. 281, 11910-11916. doi: 10.1074/jbc.M511920200

Chiang, A., Priya, R., Ramaswami, M., Vijayraghavan, K., and Rodrigues, V. (2009). Neuronal activity and Wnt signaling act through Gsk3-beta to regulate axonal integrity in mature Drosophila olfactory sensory neurons. Development 136, 1273-1282. doi: $10.1242 /$ dev. 031377

Chin, J., Angers, A., Cleary, L. J., Eskin, A., and Byrne, J. H. (2002). Transforming growth factor betal alters synapsin distribution and modulates synaptic depression in Aplysia. J. Neurosci. 22, RC220.

Chin, J., Liu, R. Y., Cleary, L. J., Eskin, A., and Byrne, J. H. (2006). TGFbetal-induced long-term changes in neuronal excitability in aplysia sensory neurons depend on MAPK. J. Neurophysiol. 95, 3286-3290. doi: 10.1152/jn.00770.2005

Chu, W. M. (2013). Tumor necrosis factor. Cancer Lett. 328, 222-225. doi: 10.1016/j.canlet.2012.10.014

Churchill, L., Rector, D. M., Yasuda, K. Fix, C., Rojas, M. J., Yasuda, T., et al. (2008). Tumor necrosis factor alpha: activity dependent expression and promotion of cortical column sleep in rats. Neuroscience 156, 71-80. doi: 10.1016/j.neuroscience 2008.06.066

Ciani, L., Boyle, K. A., Dickins, E. Sahores, M., Anane, D., Lopes, D. M., et al. (2011). Wnt7a signaling promotes dendritic spine growth and synaptic strength through $\mathrm{Ca}$ (2)(+)/Calmodulin-dependent protein kinase II. Proc. Natl. Acad. Sci. U.S.A. 108, 10732-10737. doi 10.1073/pnas. 1018132108

Ciani, L., Krylova, O., Smalley, M. J., Dale, T. C., and Salinas, P.
C. (2004). A divergent canonical WNT-signaling pathway regulates microtubule dynamics: dishevelled signals locally to stabilize microtubules. J. Cell Biol. 164, 243-253. doi: 10.1083/jcb.200309096

Colon-Ramos, D. A., Margeta, M. A., and Shen, K. (2007). Glia promote local synaptogenesis through UNC-6 (netrin) signaling in C. elegans. Science 318, 103-106. doi: 10.1126/science.1143762

Cuitino, L., Godoy, J. A., Farias, G. G., Couve, A., Bonansco, C., Fuenzalida, M., et al. (2010). Wnt-5a modulates recycling of functional GABAA receptors on hippocampal neurons. J. Neurosci. 30, 8411-8420. doi: 10.1523/JNEUROSCI.5736-09.2010

Cullen, W. K., Suh, Y. H., Anwyl, R., and Rowan, M. J. (1997). Block of LTP in rat hippocampus in vivo by betaamyloid precursor protein fragments. Neuroreport 8, 3213-3217. doi: 10.1097/00001756-19971020000006

Cumiskey, D., Butler, M. P., Moynagh, P. N., and O'Connor, J., J. (2007) Evidence for a role for the group I metabotropic glutamate receptor in the inhibitory effect of tumor necrosis factor-alpha on long-term potentiation. Brain Res. 1136, 13-19. doi: 10.1016/j.brainres.2006.12.019

Dani, N., Nahm, M., Lee, S., and Broadie, K. (2012). A targeted glycan-related gene screen reveals heparan sulfate proteoglycan sulfation regulates WNT and BMP trans-synaptic signaling. PLoS Genet. 8:e1003031. doi 10.1371/journal.pgen.1003031

Davis, E. K., Zou, Y., and Ghosh, A. (2008). Wnts acting through canonical and noncanonical signaling pathways exert opposite effects on hippocampal synapse formation. Neural Dev. 3, 32. doi: 10.1186/17498104-3-32

Denardo, L. A., De Wit, J., Otto-Hitt, S., and Ghosh, A. (2012). NGL-2 regulates input-specific synapse development in CA1 pyramidal neurons. Neuron 76, 762-775. doi: 10.1016/j.neuron.2012.10.013

Dholakiya, S. L., and Benzeroual, K. E. (2011). Protective effect of diosmin on LPS-induced apoptosis in PC12 cells and inhibition of TNF-alpha expression. Toxicol. In Vitro 25, 1039-1044. doi: 10.1016/j.tiv.2011.04.003

Diniz, L. P., Almeida, J. C., Tortelli, V., Vargas Lopes, C., Setti-Perdigao, P., Stipursky, J., et al. (2012). Astrocyte-induced synaptogenesis is mediated by transforming growth 
factor beta signaling through modulation of D-serine levels in cerebral cortex neurons. J. Biol. Chem. 287, 41432-41445. doi: 10.1074/jbc.M112.380824

Duarte, E. P., Curcio, M., Canzoniero, L. M., and Duarte, C. B. (2012). Neuroprotection by GDNF in the ischemic brain. Growth Factors 30, 242-257. doi: 10.3109/08977194.2012.691478

Dudu, V., Bittig, T., Entchev, E., Kicheva, A., Julicher, F., and Gonzalez-Gaitan, M. (2006). Postsynaptic mad signaling at the Drosophila neuromuscular junction. Curr. Biol. 16, 625-635. doi: 10.1016/j.cub.2006.02.061

Eaton, B. A., and Davis, G. W. (2005). LIM Kinasel controls synaptic stability downstream of the type II BMP receptor. Neuron 47, 695-708. doi: 10.1016/j.neuron.2005.08.010

Ellis, J. E., Parker, L., Cho, J., and Arora, K. (2010). Activin signaling functions upstream of Gbb to regulate synaptic growth at the Drosophila neuromuscular junction. Dev. Biol. 342, 121-133. doi: 10.1016/j.ydbio.2010.03.012

Fahey, T. J. 3rd., Turbeville, T., and McIntyre, K. (1995). Differential TNF secretion by wound fibroblasts compared to normal fibroblasts in response to LPS. J. Surg. Res. 58, 759-764. doi: 10.1006/jsre.1995.1120

Farias, G. G., Alfaro, I. E., Cerpa, W., Grabowski, C. P., Godoy, J. A., Bonansco, C., et al. (2009). Wnt-5a/JNK signaling promotes the clustering of PSD-95 in hippocampal neurons. J. Biol. Chem. 284, 15857-15866. doi: 10.1074/jbc.M808986200

Ferguson, A. R., Christensen, R. N., Gensel, J. C., Miller, B. A., Sun, F., Beattie, E. C., et al. (2008). Cell death after spinal cord injury is exacerbated by rapid TNF alpha-induced trafficking of GluR2-lacking AMPARs to the plasma membrane. J. Neurosci. 28, 11391-11400. doi: 10.1523/JNEUROSCI.3708-08.2008

Flores, C. (2011). Role of netrin-1 in the organization and function of the mesocorticolimbic dopamine system. J. Psychiatry Neurosci. 36, 296-310. doi: 10.1503/jpn.100171

Frankola, K. A., Greig, N. H., Luo, W., and Tweedie, D. (2011). Targeting TNF-alpha to elucidate and ameliorate neuroinflammation in neurodegenerative diseases. CNS Neurol Disord Drug Targets 10, 391-403. doi: 10.2174/187152711794653751

Fuentes-Medel, Y., Ashley, J., Barria, R., Maloney, R., Freeman,
M., and Budnik, V. (2012). Integration of a retrograde signal during synapse formation by glia-secreted TGF-beta ligand. Curr. Biol. 22, 1831-1838. doi: 10.1016/j.cub.2012.07.063

Fukushima, T., Liu, R. Y., and Byrne, J. H. (2007). Transforming growth factor-beta2 modulates synaptic efficacy and plasticity and induces phosphorylation of CREB in hippocampal neurons. Hippocampus 17, 5-9. doi: 10.1002/hipo.20243

Furukawa, K., and Mattson, M. P. (1998). The transcription factor NF-kappaB mediates increases in calcium currents and decreases in NMDA- and AMPA/kainateinduced currents induced by tumor necrosis factor-alpha in hippocampal neurons. J. Neurochem. 70, 1876-1886. doi: 10.1046/j.14714159.1998.70051876.x

Gogolla, N., Galimberti, I., Deguchi, Y., and Caroni, P. (2009). Wnt signaling mediates experience-related regulation of synapse numbers and mossy fiber connectivities in the adult hippocampus. Neuron 62, 510-525. doi: 10.1016/j.neuron.2009.04.022

Grant, A., Hoops, D., Labelle-Dumais, C., Prevost, M., Rajabi, H., Kolb, B., et al. (2007). Netrin-1 receptordeficient mice show enhanced mesocortical dopamine transmission and blunted behavioural responses to amphetamine. Eur. J. Neurosci. 26, 3215-3228. doi: 10.1111/j.1460-9568.2007.05888.x

Hall, A. C., Lucas, F. R., and Salinas, P. C. (2000). Axonal remodeling and synaptic differentiation in the cerebellum is regulated by WNT-7a signaling. Cell 100, 525-535. doi: 10.1016/S0092-8674 (00)80689-3

He, P., Liu, Q., Wu, J., and Shen, Y. (2012). Genetic deletion of TNF receptor suppresses excitatory synaptic transmission via reducing AMPA receptor synaptic localization in cortical neurons. FASEB J. 26, 334-345. doi: 10.1096/ff.11-192716

Henriquez, J. P., Webb, A., Bence, M., Bildsoe, H., Sahores, M., Hughes, S. M., et al. (2008). Wnt signaling promotes AChR aggregation at the neuromuscular synapse in collaboration with agrin. Proc. Natl. Acad. Sci. U.S.A. 105, 18812-18817. doi: 10.1073/pnas.0806300105

Heupel, K., Sargsyan, V., Plomp, J. J., Rickmann, M., Varoqueaux, F., Zhang, W., et al. (2008). Loss of transforming growth factor-beta 2 leads to impairment of central synapse function. Neural Dev. 3, 25. doi: 10.1186/1749-8104-3-25
Hoffmann, O., Zipp, F., and Weber, J. R. (2009). Tumour necrosis factorrelated apoptosis-inducing ligand (TRAIL) in central nervous system inflammation. J. Mol. Med. (Berl.) 87, 753-763. doi: 10.1007/s00109009-0484-x

Horiuchi, T., Mitoma, H., Harashima, S., Tsukamoto, H., and Shimoda, T. (2010). Transmembrane TNF-alpha: structure, function and interaction with antiTNF agents. Rheumatology (Oxford) 49, 1215-1228. doi 10.1093/rheumatology/keq031

Horn, K. E., Glasgow, S. D., Gobert, D., Bull, S. J., Luk, T., Girgis, J., et al. (2013). DCC expression by neurons regulates synaptic plasticity in the adult brain. Cell Rep. 3, 173-185. doi: 10.1016/j.celrep.2012.12.005

Ikeda, H., Tsuda, M., Inoue, K., and Murase, K. (2007). Long-term potentiation of neuronal excitation by neuron-glia interactions in the rat spinal dorsal horn. Eur. J. Neurosci. 25, 1297-1306. doi: 10.1111/j.1460-9568.2007.05386.x

Inaki, M., Yoshikawa, S., Thomas, J. B. Aburatani, H., and Nose, A. (2007). Wnt4 is a local repulsive cue that determines synaptic target specificity. Curr. Biol. 17, 1574-1579. doi: 10.1016/j.cub.2007.08.013

Inokuchi, K., Kato, A., Hiraia, K., Hishinuma, F., Inoue, M., and Ozawa, F. (1996). Increase in activin beta A mRNA in rat hippocampus during long-term potentiation. FEBS Lett. 382, 48-52. doi: 10.1016/0014-5793(96)00135-4

Ishii, N., Wadsworth, W. G., Stern, B. D., Culotti, J. G., and Hedgecock, E. M. (1992). UNC-6, a lamininrelated protein, guides cell and pioneer axon migrations in $C$. elegans. Neuron 9, 873-881. doi: 10.1016/0896-6273(92)90240-E

Itoh, A., Akaike, T., Sokabe, M., Nitta, A., Iida, R., Olariu, A., et al. (1999). Impairments of long-term potentiation in hippocampal slices of beta-amyloid-infused rats. Eur. J. Pharmacol. 382, 167-175. doi 10.1016/S0014-2999(99)00601-9

James, R. E., and Broihier, H. T. (2011). Crimpy inhibits the BMP homolog Gbb in motoneurons to enable proper growth control at the Drosophila neuromuscular junction. Development 138 3273-3286. doi: $10.1242 / \mathrm{dev}$ 066142

Janelsins, M. C., Mastrangelo, M. A., Park, K. M., Sudol, K. L., Narrow, W. C., Oddo, S., et al. (2008). Chronic neuron-specific tumor necrosis factor-alpha expression enhances the local inflammatory environment ultimately leading to neuronal death in 3xTg-AD mice. Am. J. Pathol. 173, 1768-1782. doi: 10.2353/ajpath.2008.080528

Jensen, M., Hoerndli, F. J., Brockie, P. J., Wang, R., Johnson, E., Maxfield, D., et al. (2012). Wnt signaling regulates acetylcholine receptor translocation and synaptic plasticity in the adult nervous system. Cell 149, 173-187. doi: 10.1016/j.cell.2011.12.038

Jing, L., Lefebvre, J. L., Gordon, L. R., and Granato, M. (2009). Wnt signals organize synaptic prepattern and axon guidance through the zebrafish unplugged/MuSK receptor. Neuron 61, 721-733. doi: 10.1016/j.neuron.2008.12.025

Jo, J., Whitcomb, D. J., Olsen, K. M., Kerrigan, T. L., Lo, S. C., Bru-Mercier, G., et al. (2011) Abeta(1-42) inhibition of LTP is mediated by a signaling pathway involving caspase-3, Aktl and GSK3beta. Nat. Neurosci. 14, 545-547. doi: 10.1038/nn.2785

Jovinge, S., Ares, M. P., Kallin, B., and Nilsson, J. (1996). Human monocytes/macrophages release TNF-alpha in response to $\mathrm{Ox}$ LDL. Arterioscler. Thromb. Vasc. Biol. 16, 1573-1579. doi: 10.1161/01.ATV.16.12.1573

Kamimura, K., Ueno, K., Nakagawa, J., Hamada, R., Saitoe, M., and Maeda, N. (2013). Perlecan regulates bidirectional Wnt signaling at the Drosophila neuromuscular junction. J. Cell Biol. 200, 219-233. doi: $10.1083 /$ jcb.201207036

Kawasaki, Y., Zhang, L., Cheng, J. K., and Ji, R. R. (2008). Cytokine mechanisms of central sensitization: distinct and overlapping role of interleukin1beta, interleukin-6, and tumor necrosis factor-alpha in regulating synaptic and neuronal activity in the superficial spinal cord. J. Neurosci. 28, 5189-5194. doi: 10.1523/JNEUROSCI.3338-07.2008

Kellom, M., Basselin, M., Keleshian, V. L., Chen, M., Rapoport, S. I., and Rao, J. S. (2012). Dose-dependent changes in neuroinflammatory and arachidonic acid cascade markers with synaptic marker loss in rat lipopolysaccharide infusion model of neuroinflammation. BMC Neurosci. 13:50. doi: 10.1186/1471-2202-13-50

Kim, N. C., and Marques, G. (2010). Identification of downstream targets of the bone morphogenetic protein pathway in the Drosophila nervous system. Dev. Dyn. 239, 2413-2425. doi: $10.1002 /$ dvdy.22368 
Kim, N. C., and Marques, G. (2012). The Ly6 neurotoxin-like molecule target of wit regulates spontaneous neurotransmitter release at the developing neuromuscular junction in Drosophila. Dev. Neurobiol. 72, 1541-1558. doi: 10.1002/dneu. 22021

Kim, S., Burette, A., Chung, H. S., Kwon, S. K., Woo, J., Lee, H. W., et al. (2006). NGL family PSD-95interacting adhesion molecules regulate excitatory synapse formation. Nat. Neurosci. 9, 1294-1301. doi: $10.1038 / \mathrm{nn} 1763$

Kimura, R., Mactavish, D., Yang, J., Westaway, D., and Jhamandas, J. H. (2012). Beta amyloid-induced depression of hippocampal longterm potentiation is mediated through the amylin receptor. J. Neurosci. 32, 17401-17406. doi: 10.1523/JNEUROSCI.302812.2012

Klassen, M. P., and Shen, K. (2007). Wnt signaling positions neuromuscular connectivity by inhibiting synapse formation in C. elegans. Cell 130, 704-716. doi: 10.1016/j.cell.2007.06.046

Ko, S. Y., Dass, C. R., and Nurgali, K. (2012). Netrin-1 in the developing enteric nervous system and colorectal cancer. Trends Mol. Med. 18, 544-554. doi: 10.1016/j.molmed.2012.07.001

Koles, K., and Budnik, V. (2012). Wnt signaling in neuromuscular junction development. Cold Spring Harb. Perspect. Biol. 4, 1-22. doi: 10.1101/cshperspect.a008045

Korkut, C., Ataman, B. Ramachandran, P., Ashley, J., Barria, R., Gherbesi, N., et al. (2009). Trans-synaptic transmission of vesicular Wnt signals through Evi/Wntless. Cell 139, 393-404. doi: 10.1016/j.cell.2009.07.051

Kotilinek, L. A., Westerman, M. A., Wang, Q., Panizzon, K., Lim, G. P., Simonyi, A., et al. (2008). Cyclooxygenase-2 inhibition improves amyloid-beta-mediated suppression of memory and synaptic plasticity. Brain 131, 651-664. doi: 10.1093/brain/ awn008

Krieglstein, K., Zheng, F., Unsicker, K., and Alzheimer, C. (2011). More than being protective: functional roles for TGF-beta/activin signaling pathways at central synapses. Trends Neurosci. 34, 421-429. doi: 10.1016/j.tins.2011.06.002

Krylova, O., Herreros, J., Cleverley, K. E., Ehler, E., Henriquez, J. P., Hughes, S. M., et al. (2002). WNT3 , expressed by motoneurons, regulates terminal arborization of neurotrophin-3-responsive spinal sensory neurons. Neuron 35, 1043-1056. doi: 10.1016/S08966273(02)00860-7

Kubiczkova, L., Sedlarikova, L., Hajek, R., and Sevcikova, S. (2012). TGFbeta - an excellent servant but a bad master. J. Transl. Med. 10, 183. doi: 10.1186/1479-5876-10-183

Kuhl, M., Sheldahl, L. C., Park, M., Miller, J. R., and Moon, R. T. (2000). The Wnt/Ca2+ pathway: a new vertebrate Wnt signaling pathway takes shape. Trends Genet. 16, 279-283. doi: 10.1016/S01689525(00)02028-X

Kurisaki, A., Inoue, I., Kurisaki, K., Yamakawa, N., Tsuchida, K., and Sugino, H. (2008). Activin induces long-lasting N-methyl-Daspartate receptor activation via scaffolding PDZ protein activin receptor interacting protein 1 . Neuroscience 151, 1225-1235. doi: 10.1016/j.neuroscience.2007.12.012

Lacmann, A., Hess, D., Gohla, G., Roussa, E., and Krieglstein, K. (2007). Activity-dependent release of transforming growth factor-beta in a neuronal network in vitro. Neuroscience 150, 647-657. doi: 10.1016/j.neuroscience.2007.09.046

Lai Wing Sun, K., Correia, J. P., and Kennedy, T. E. (2011). Netrins: versatile extracellular cues with diverse functions. Development 138, 2153-2169. doi: 10.1242/dev.044529

Lambert, M. P., Barlow, A. K., Chromy, B. A., Edwards, C., Freed, R., Liosatos, M., et al. (1998). Diffusible, nonfibrillar ligands derived from Abeta1-42 are potent central nervous system neurotoxins. Proc. Natl. Acad. Sci. U.S.A. 95, 6448-6453. doi: 10.1073/pnas.95.11.6448

Leonoudakis, D., Zhao, P., and Beattie, E. C. (2008). Rapid tumor necrosis factor alpha-induced exocytosis of glutamate receptor 2-lacking AMPA receptors to extrasynaptic plasma membrane potentiates excitotoxicity. J. Neurosci. 28, 2119-2130. doi: 10.1523/JNEUROSCI.5159-07. 2008

Li, P., Collins, K. M., Koelle, M. R., and Shen, K. (2013a). LIN-12/Notch signaling instructs postsynaptic muscle arm development by regulating UNC-40/DCC and MADD2 in Caenorhabditis elegans. Elife 2:e00378. doi: 10.7554/eLife.00378

Li, S., Jin, M., Zhang, D., Yang, T., Koeglsperger, T., Fu, H., et al. (2013b). Environmental novelty activates beta2-adrenergic signaling to prevent the impairment of hippocampal LTP by Abeta oligomers. Neuron 77, 929-941. doi: 10.1016/j.neuron.2012.12.040

Li, R., Yang, L., Lindholm, K., Konishi, Y., Yue, X., Hampel, H., et al. (2004a). Tumor necrosis factor death receptor signaling cascade is required for amyloid-beta protein-induced neuron death. J. Neurosci. 24, 1760-1771. doi: 10.1523/JNEUROSCI.4580-03.2004

Li, W., Lee, J., Vikis, H. G., Lee, S. H., Liu, G., Aurandt, J., et al. (2004b). Activation of FAK and Src are receptor-proximal events required for netrin signaling. Nat. Neurosci. 7, 1213-1221. doi: 10.1038/nn1329

Li, S., Jin, M., Koeglsperger, T., Shepardson, N. E., Shankar, G. M., and Selkoe, D. J. (2011). Soluble Abeta oligomers inhibit long-term potentiation through a mechanism involving excessive activation of extrasynaptic NR2Bcontaining NMDA receptors. J. Neurosci. 31, 6627-6638. doi: 10.1523/JNEUROSCI.0203-11.2011

Li, X. M., Dong, X. P., Luo, S. W., Zhang, B., Lee, D. H., Ting, A. K., et al. (2008). Retrograde regulation of motoneuron differentiation by muscle beta-catenin. Nat. Neurosci. 11, 262-268. doi: 10.1038/nn2053

Liebl, F. L., Wu, Y., Featherstone, D. E., Noordermeer, J. N., Fradkin, L., and Hing, H. (2008). Derailed regulates development of the Drosophila neuromuscular junction. Dev. Neurobiol. 68, 152-165. doi: 10.1002/dneu. 20562

Lim, B. K., Cho, S. J., Sumbre, G., and Poo, M. M. (2010). Region-specific contribution of ephrin-B and Wnt signaling to receptive field plasticity in developing optic tectum. Neuron 65, 899-911. doi: 10.1016/j.neuron. 2010.03 .008

Lin, J. C., Ho, W. H., Gurney, A., and Rosenthal, A. (2003). The netrinG1 ligand NGL-1 promotes the outgrowth of thalamocortical axons. Nat. Neurosci. 6, 1270-1276. doi: 10.1038/nn 1148

Liu, M. C., Liu, X. Q., Wang, W., Shen, X. F., Che, H. L., Guo, Y. Y., et al. (2012). Involvement of microglia activation in the lead induced long-term potentiation impairment. PLOS ONE 7:e43924. doi: 10.1371/journal.pone.0043924

Liu, Y. L., Zhou, L. J., Hu, N. W. $\mathrm{Xu}$, J. T., Wu, C. Y., Zhang, T., et al. (2007). Tumor necrosis factor-alpha induces long-term potentiation of C-fiber evoked field potentials in spinal dorsal horn in rats with nerve injury: the role of NF-kappa B, JNK and p38 MAPK. Neuropharmacology 52, 708-715. doi: $\quad 10.1016 /$ j.neuropharm.2006 09.011

Livesey, F. J., and Hunt, S. P. (1997). Netrin and netrin receptor expression in the embryonic mammalian nervous system suggests roles in retinal, striatal, nigral, and cerebellar development. Mol. Cell. Neurosci. 8, 417-429. doi: 10.1006/mcne. 1997.0598

Logan, C. Y., and Nusse, R. (2004). The Wnt signaling pathway in development and disease. Annu. Rev. Cell Dev. Biol. 20, 781-810. doi: 10.1146/annurev.cellbio.20.010403. 113126

Luo, Z. G., Wang, Q., Zhou, J. Z., Wang, J., Luo, Z., Liu, M., et al. (2002). Regulation of AChR clustering by Dishevelled interacting with MuSK and PAK1. Neuron 35, 489-505. doi: 10.1016/S0896-6273(02)00783-3

Manitt, C., and Kennedy, T. E. (2002). Where the rubber meets the road: netrin expression and function in developing and adult nervous systems. Prog. Brain Res. 137, 425-442. doi: 10.1016/S0079-6123(02)37034-1

Manitt, C., Mimee, A., Eng, C., Pokinko, M., Stroh, T., Cooper, H. M., et al. (2011). The netrin receptor DCC is required in the pubertal organization of mesocortical dopamine circuitry. J. Neurosci. 31, 8381-8394. doi: 10.1523/JNEUROSCI.0606-11.2011

Manitt, C., Nikolakopoulou, A. M., Almario, D. R., Nguyen, S. A., and Cohen-Cory, S. (2009). Netrin participates in the development of retinotectal synaptic connectivity by modulating axon arborization and synapse formation in the developing brain. J. Neurosci. 29, 11065-11077. doi: 10.1523/JNEUROSCI.0947-09.2009

Marie, B., Pym, E., Bergquist, S., and Davis, G. W. (2010). Synaptic homeostasis is consolidated by the cell fate gene gooseberry, a Drosophila pax3/7 homolog. J. Neurosci. 30, 8071-8082. doi: 10.1523/JNEUROSCI.5467-09.2010

Marques, G., Bao, H., Haerry, T. E., Shimell, M. J., Duchek, P., Zhang, B., et al. (2002). The Drosophila BMP type II receptor Wishful Thinking regulates neuromuscular synapse morphology and function. Neuron 33, 529-543. doi: 10.1016/S08966273(02)00595-0

Massague, J. (2012a). TGF-beta signaling in development and disease. FEBS Lett. 586, 1833. doi: 10.1016/j.febslet.2012.05.030

Massague, J. (2012b). TGFbeta signalling in context. Nat. Rev. 
Mol. Cell Biol. 13, 616-630. doi: 10.1038/nrm3434

Mathew, D., Ataman, B., Chen, J., Zhang, Y., Cumberledge, S., and Budnik, V. (2005). Wingless signaling at synapses is through cleavage and nuclear import of receptor DFrizzled2. Science 310, 1344-1347. doi: 10.1126/science.1117051

McCabe, B. D., Hom, S., Aberle, H., Fetter, R. D., Marques, G., Haerry, T. E., et al. (2004). Highwire regulates presynaptic BMP signaling essential for synaptic growth. Neuron 41, 891-905. doi: 10.1016/S08966273(04)00073-X

McCabe, B. D., Marques, G., Haghighi, A. P., Fetter, R. D., Crotty, M. L., Haerry, T. E., et al. (2003). The BMP homolog Gbb provides a retrograde signal that regulates synaptic growth at the Drosophila neuromuscular junction. Neuron 39, 241-254. doi: 10.1016/S0896-6273(03)00426-4

McCoy, M. K., and Tansey, M. G. (2008). TNF signaling inhibition in the CNS: implications for normal brain function and neurodegenerative disease. J. Neuroinflammation 5 , 45. doi: 10.1186/1742-2094-5-45

Mc Guire, C., Beyaert, R., and Van Loo, G. (2011). Death receptor signalling in central nervous system inflammation and demyelination. Trends Neurosci. 34, 619-628. doi: 10.1016/j.tins.2011.09.002

Miech, C., Pauer, H. U., He, X., and Schwarz, T. L. (2008). Presynaptic local signaling by a canonical wingless pathway regulates development of the Drosophila neuromuscular junction. J. Neurosci. 28, 10875-10884. doi: 10.1523/JNEUROSCI.0164-08.2008

Mlodzik, M. (2002). Planar cell polarization: do the same mechanisms regulate Drosophila tissue polarity and vertebrate gastrulation. Trends Genet. 18, 564-571. doi: 10.1016/S0168-9525(02)02770-1

Muller, M. R., Zheng, F., Werner, S., and Alzheimer, C. (2006). Transgenic mice expressing dominant-negative activin receptor IB in forebrain neurons reveal novel functions of activin at glutamatergic synapses. J. Biol. Chem. 281, 29076-29084. doi: 10.1074/jbc. M604959200

Mulligan, K. A., and Cheyette, B. N. (2012). Wnt signaling in vertebrate neural development and function. J. Neuroimmune. Pharmacol. 7 , 774-787. doi: 10.1007/s11481-0129404-x

Nahm, M., Kim, S., Paik, S. K., Lee, M., Lee, S., Lee, Z. H., et al. (2010a). dCIP4 (Drosophila
Cdc42-interacting protein 4) restrains synaptic growth by inhibiting the secretion of the retrograde Glass bottom boat signal. J. Neurosci. 30, 8138-8150. doi: 10.1523/JNEUROSCI.0256-10.2010

Nahm, M., Long, A. A., Paik, S. K., Kim, S., Bae, Y. C., Broadie, K., et al. (2010b). The Cdc42selective GAP rich regulates postsynaptic development and retrograde BMP transsynaptic signaling. J. Cell Biol. 191, 661-675. doi: 10.1083/jcb.201007086

Nahm, M., Lee, M. J., Parkinson, W., Lee, M., Kim, H., Kim, Y J., et al. (2013). Spartin regulates synaptic growth and neuronal survival by Inhibiting BMP-mediated microtubule stabilization. Neuron 77, 680-695. doi: 10.1016/j.neuron.2012.12.015

Nakashiba, T., Ikeda, T., Nishimura, S., Tashiro, K., Honjo, T., Culotti, J. G., et al. (2000). Netrin-G1: a novel glycosyl phosphatidylinositollinked mammalian netrin that is functionally divergent from classical netrins. J Neurosci. 20, 6540-6550.

Nakashiba, T., Nishimura, S., Ikeda, T., and Itohara, S. (2002). Complementary expression and neurite outgrowth activity of netrin-G subfamily members. Mech. Dev. 111, 47-60. doi: 10.1016/S0925-4773(01)00600-1

Niehrs, C. (2006). Function and biological roles of the Dickkopf family of Wnt modulators. Oncogene 25, 7469-7481. doi: 10.1038/sj.onc. 1210054

Nishimura-Akiyoshi, S., Niimi, K., Nakashiba, T., and Itohara, S. (2007). Axonal netrin-Gs transneuronally determine lamina-specific subdendritic segments. Proc. Natl. Acad. Sci. U.S.A. 104, 14801-14806. doi: 10.1073/pnas.0706919104

O'Connor, J. J. (2013). Targeting tumour necrosis factor-alpha in hypoxia and synaptic signalling. Ir. J. Med. Sci. 182, 157-162. doi: 10.1007/S11845-013-0911-4

O'Connor-Giles, K. M., Ho, L. L. and Ganetzky, B. (2008). Nervous wreck interacts with thickveins and the endocytic machinery to attenuate retrograde BMP signaling during synaptic growth. Neuron 58, 507-518. doi: 10.1016/j.neuron. 2008.03.007

Olsen, K. M., and Sheng, M. (2012). NMDA receptors and BAX are essential for Abeta impairment of LTP. Sci. Rep. 2, 225. doi: 10.1038/srep00225

Ou, C. Y., Poon, V. Y., Maeder, C. I., Watanabe, S., Lehrman, E. K., Fu, A. K., et al. (2010). Two cyclin-dependent kinase pathways are essential for polarized trafficking of presynaptic components. Cell 141, 846-858. doi: 10.1016/j.cell.2010.04.011

Packard, M., Koo, E. S., Gorczyca, M., Sharpe, J., Cumberledge, S., and Budnik, V. (2002). The Drosophila Wnt, wingless, provides an essential signal for pre- and postsynaptic differentiation. Cell 111, 319-330. doi 10.1016/S0092-8674(02)01047-4

Paganoni, S., Bernstein, J., and Ferreira, A. (2010). Ror1-Ror2 complexes modulate synapse formation in hippocampal neurons. Neuroscience 165, 1261-1274. doi 10.1016/j.neuroscience.2009.11.056

Pan, Y., Liu, G., Fang, M., Shen, L., Wang, L., Han, Y., et al. (2010). Abnormal expression of netrin-G2 in temporal lobe epilepsy neurons in humans and a rat model. Exp. Neurol. 224, 340-346. doi: 10.1016/j.expneurol. 2010.04.001

Park, C. K., Lu, N., Xu, Z. Z., Liu, T., Serhan, C. N., and Ji, R. R. (2011a). Resolving TRPV1- and TNF-alpha-mediated spinal cord synaptic plasticity and inflammatory pain with neuroprotectin D1. J. Neurosci. 31, 15072-15085. doi 10.1523/JNEUROSCI.2443-11.2011

Park, M., Watanabe, S., Poon, V. Y., Ou, C. Y., Jorgensen, E. M., and Shen, K. (2011b). CYY-1/cyclin $\mathrm{Y}$ and CDK-5 differentially regulate synapse elimination and formation for rewiring neural circuits. Neuron 70, 742-757. doi 10.1016/j.neuron.2011.04.002

Park, H., and Poo, M. M. (2013). Neurotrophin regulation of neural circuit development and function. Nat. Rev. Neurosci. 14, 7-23. doi: 10.1038/nrn3379

Pickering, M., Cumiskey, D., and O'Connor, J. J. (2005). Actions of TNF-alpha on glutamatergic synaptic transmission in the central nervous system. Exp. Physiol. 90 663-670. doi: 10.1113/expphysiol. 2005.030734

Plant, K., Pelkey, K. A., Bortolotto, Z. A., Morita, D., Terashima, A., McBain, C. J., et al. (2006). Transient incorporation of native GluR2-lacking AMPA receptors during hippocampal long-term potentiation. Nat. Neurosci. 9, 602-604. doi: 10.1038/ nn1678

Poon, V. Y., Klassen, M. P., and Shen, K. (2008). UNC-6/netrin and its receptor UNC-5 locally exclude presynaptic components from dendrites. Nature 455, 669-673. doi: 10.1038/nature07291
Rajasekharan, S., and Kennedy, T. E. (2009). The netrin protein family. Genome Biol. 10, 239. doi: 10.1186/gb-2009-10-9-239

Rao, J. S., Kellom, M., Kim, H. W., Rapoport, S. I., and Reese, E. A. (2012). Neuroinflammation and synaptic loss. Neurochem. Res. 37, 903-910. doi: 10.1007/s11064-0120708-2

Rattner, A., Hsieh, J. C., Smallwood, P. M., Gilbert, D. J., Copeland, N. G., Jenkins, N. A., et al. (1997). A family of secreted proteins contains homology to the cysteinerich ligand-binding domain of frizzled receptors. Proc. Natl. Acad. Sci. U.S.A. 94, 2859-2863. doi: 10.1073/pnas.94.7.2859

Rawson, J. M., Lee, M., Kennedy, E. L., and Selleck, S. B. (2003). Drosophila neuromuscular synapse assembly and function require the TGF-beta type I receptor saxophone and the transcription factor Mad. J. Neurobiol. 55, 134-150. doi: 10.1002/neu.10189

Raymond, C. R., Ireland, D. R., and Abraham, W. C. (2003). NMDA receptor regulation by amyloid-beta does not account for its inhibition of LTP in rat hippocampus. Brain Res. 968, 263-272. doi: 10.1016/S00068993(03)02269-8

Sahores, M., Gibb, A., and Salinas, P. C. (2010). Frizzled-5, a receptor for the synaptic organizer Wnt7a, regulates activity-mediated synaptogenesis. Development 137, 2215-2225. doi: $10.1242 / \mathrm{dev} .046722$

Salie, R., Niederkofler, V., and Arber, S. (2005). Patterning molecules; multitasking in the nervous system. Neuron 45 , 189-192.

Salinas, P. C. (2012). Wnt signaling in the vertebrate central nervous system: from axon guidance to synaptic function. Cold Spring Harb. Perspect. Biol. 4, 1-14. doi: 10.1101/cshperspect.a008003

Santello, M., and Volterra, A. (2012). TNFalpha in synaptic function: switching gears. Trends Neurosci. 35, 638-647. doi: 10.1016/j.tins.2012.06.001

Schneider-Brachert, W., Tchikov, V., Neumeyer, J., Jakob, M., WinotoMorbach, S., Held-Feindt, J., et al. (2004). Compartmentalization of TNF receptor 1 signaling: internalized TNF receptosomes as death signaling vesicles. Immunity 21, 415-428. doi: 10.1016/j.immuni.2004.08.017

Sekiguchi, M., Hayashi, F., Tsuchida, K., and Inokuchi, K. (2009). Neuron type-selective effects of activin on development of the hippocampus. 
Neurosci. Lett. 452, 232-237. doi: 10.1016/j.neulet.2009.01.074

Shen, K., and Cowan, C. W. (2010). Guidance molecules in synapse formation and plasticity. Cold Spring Harb. Perspect. Biol. 2:a001842. doi: $10.1101 /$ cshperspect.a001842

Shen, K., and Scheiffele, P. (2010). Genetics and cell biology of building specific synaptic connectivity. Annu. Rev. Neurosci. 33, 473-507. doi: 10.1146/annurev.neuro.051508. 135302

Shi, Y., and Massague, J. (2003). Mechanisms of TGF-beta signaling from cell membrane to the nucleus. Cell 113, 685-700. doi: 10.1016/S0092-8674(03)00432-X

Shoji-Kasai, Y., Ageta, H., Hasegawa, Y., Tsuchida, K., Sugino, H., and Inokuchi, K. (2007). Activin increases the number of synaptic contacts and the length of dendritic spine necks by modulating spinal actin dynamics. J. Cell. Sci. 120, 3830-3837. doi: 10.1242/jcs.012450

Singh, A. P., Vijayraghavan, K., and Rodrigues, V. (2010). Dendritic refinement of an identified neuron in the Drosophila CNS is regulated by neuronal activity and Wnt signaling. Development 137, 1351-1360. doi: 10.1242/dev.044131

Smith, J. A., Das, A., Ray, S. K., and Banik, N. L. (2012a). Role of pro-inflammatory cytokines released from microglia in neurodegenerative diseases. Brain Res. Bull. 87, 10-20. doi: 10.1016/j.brainresbull.2011.10.004

Smith, R. B., Machamer, J. B., Kim, N. C., Hays, T. S., and Marques, G. (2012b). Relay of retrograde synaptogenic signals through axonal transport of BMP receptors. J. Cell. Sci. 125, 3752-3764. doi: 10.1242/jcs.094292

Specht, H., Peterziel, H., Bajohrs, M., Gerdes, H. H., Krieglstein, K., and Unsicker, K. (2003). Transforming growth factor beta2 is released from PC12 cells via the regulated pathway of secretion. Mol. Cell. Neurosci. 22, 75-86. doi: 10.1016/S1044-7431(02)00023-4

Speese, S. D., and Budnik, V. (2007). Wnts: up-andcoming at the synapse. Trends Neurosci. 30, 268-275. doi: 10.1016/j.tins.2007.04.003

Speese, S. D., Ashley, J., Jokhi, V., Nunnari, J., Barria, R., Li, Y., et al. (2012). Nuclear envelope budding enables large ribonucleoprotein particle export during synaptic Wnt signaling. Cell 149, 832-846. doi: 10.1016/j.cell.2012. 03.032
Stavoe, A. K., and Colon-Ramos, D. A. (2012). Netrin instructs synaptic vesicle clustering through Rac GTPase, MIG-10, and the actin cytoskeleton. J. Cell Biol. 197, 75-88. doi: 10.1083/jcb.2011 10127

Stavoe, A. K., Nelson, J. C., MartinezVelazquez, L. A., Klein, M., Samuel, A. D., and ColonRamos, D. A. (2012). Synaptic vesicle clustering requires a distinct MIG-10/Lamellipodin isoform and ABI-1 downstream from Netrin. Genes Dev. 26, 2206-2221. doi: 10.1101/gad. 193409.112

Steinmetz, C. C., and Turrigiano, G. G. (2010). Tumor necrosis factor-alpha signaling maintains the ability of cortical synapses to express synaptic scaling. J. Neurosci. 30, 14685-14690. doi: 10.1523/JNEUROSCI.2210-10.2010 Stellwagen, D., Beattie, E. C., Seo, J. Y., and Malenka, R. C. (2005). Differential regulation of AMPA receptor and GABA receptor trafficking by tumor necrosis factor-alpha. J. Neurosci. 25, 3219-3228. doi: 10.1523/JNEUROSCI.4486-04.2005 Stellwagen, D., and Malenka, R. C. (2006). Synaptic scaling mediated by glial TNF-alpha. Nature 440, 1054-1059. doi: 10.1038/nature04671

Stephan, A., Laroche, S., and Davis, S. (2001). Generation of aggregated beta-amyloid in the rat hippocampus impairs synaptic transmission and plasticity and causes memory deficits. J. Neurosci. 21, 5703-5714.

Sun, M., Gewirtz, J. C., Bofenkamp, L., Wickham, R. J., Ge, H., and O'Connor, M. B. (2010). Canonical TGF-beta signaling is required for the balance of excitatory/inhibitory transmission within the hippocampus and prepulse inhibition of acoustic startle. J. Neurosci. 30, 6025-6035. doi: 10.1523/ JNEUROSCI.0789-10.2010

Sun, M., Thomas, M. J., Herder, R., Bofenkamp, M. L., Selleck, S. B., and O'Connor, M. B. (2007). Presynaptic contributions of chordin to hippocampal plasticity and spatial learning. J. Neurosci. 27, 7740-7750. doi: 10.1523/JNEUROSCI.1604-07.2007

Sweeney, S. T., and Davis, G. W. (2002). Unrestricted synaptic growth in spinster-a late endosomal protein implicated in TGF-beta-mediated synaptic growth regulation. Neuron 36, 403-416. doi: 10.1016/S08966273(02)01014-0
Tarkowski, E. (2002). Cytokines in dementias. Curr. Drug Targets. Inflamm. Allergy 1, 193-200. doi: 10.2174/1568010023344670

Ting, C. Y., Herman, T., Yonekura, S., Gao, S., Wang, J., Serpe, M., et al. (2007). Tiling of r7 axons in the Drosophila visual system is mediated both by transduction of an activin signal to the nucleus and by mutual repulsion. Neuron 56, 793-806. doi: 10.1016/j.neuron.2007.09.033

Tsai, P. I., Wang, M., Kao, H. H., Cheng, Y. J., Lin, Y. J., Chen, R. H., et al. (2012). Activity-dependent retrograde laminin A signaling regulates synapse growth at Drosophila neuromuscular junctions. Proc. Natl. Acad. Sci. U.S.A. 109, 17699-17704. doi: 10.1073/pnas.1206416109

Varela-Nallar, L., Alfaro, I. E., Serrano, F. G., Parodi, J., and Inestrosa, N. C. (2010). Wingless-type family member $5 \mathrm{~A}$ (Wnt-5a) stimulates synaptic differentiation and function of glutamatergic synapses. Proc. Natl. Acad. Sci. U.S.A. 107, 21164-21169. doi: 10.1073/pnas. 1010011107

Varela-Nallar, L., Grabowski, C. P., Alfaro, I. E., Alvarez, A. R., and Inestrosa, N. C. (2009). Role of the Wnt receptor Frizzled-1 in presynaptic differentiation and function. Neural Dev. 4, 41. doi: 10.1186/1749-8104-4-41

Varela-Nallar, L., Parodi, J., Farias, G. G., and Inestrosa, N. C. (2012). Wnt-5a is a synaptogenic factor with neuroprotective properties against Abeta toxicity. Neurodegener. Dis. 10, 23-26. doi: $10.1159 / 000333360$

Vitolo, O. V., Sant'angelo, A., Costanzo, V., Battaglia, F., Arancio, O., and Shelanski, M. (2002). Amyloid beta -peptide inhibition of the PKA/CREB pathway and longterm potentiation: reversibility by drugs that enhance cAMP signaling. Proc. Natl. Acad. Sci. U.S.A. 99, 13217-13221. doi: $10.1073 /$ pnas. 172504199

Walsh, D. M., Klyubin, I., Fadeeva, J. V., Rowan, M. J., and Selkoe, D. J. (2002). Amyloid-beta oligomers: their production, toxicity and therapeutic inhibition. Biochem. Soc. Trans. 30, 552-557. doi: 10.1042/BST0300552

Wang, J., Jing, Z., Zhang, L., Zhou, G., Braun, J., Yao, Y., et al. (2003). Regulation of acetylcholine receptor clustering by the tumor suppressor APC. Nat. Neurosci. 6, 1017-1018. doi: $10.1038 / \mathrm{nn} 1128$

Wang, J., Ruan, N. J., Qian, L., Lei, W. L., Chen, F., and Luo, Z. G. (2008). Wnt/beta-catenin signaling suppresses Rapsyn expression and inhibits acetylcholine receptor clustering at the neuromuscular junction. J. Biol. Chem. 283, 21668-21675. doi: 10.1074/jbc.M709939200

Wang, Q., Wu, J., Rowan, M. J., and Anwyl, R. (2005). Betaamyloid inhibition of long-term potentiation is mediated via tumor necrosis factor. Eur. J. Neurosci. 22, 2827-2832. doi: $\quad 10.1111 / \mathrm{j} .1460-9568.2005$ 04457.x

Wang, X., Shaw, W. R., Tsang, H. T., Reid, E., and O'kane, C. J. (2007). Drosophila spichthyin inhibits BMP signaling and regulates synaptic growth and axonal microtubules. Nat. Neurosci. 10, 177-185. doi: 10.1038/nn1841

Watters, O., and O'Connor, J. J. (2011). A role for tumor necrosis factoralpha in ischemia and ischemic preconditioning. J. Neuroinflammation 8:87. doi: 10.1186/1742-2094-8-87

Wayman, G. A., Impey, S., Marks, D., Saneyoshi, T., Grant, W F., Derkach, V., et al. (2006). Activity-dependent dendritic arborization mediated by CaMkinase I activation and enhanced CREB-dependent transcription of Wnt-2. Neuron 50, 897-909. doi: 10.1016/j.neuron.2006.05.008

Wei, X. H., Zang, Y., Wu, C. Y., $\mathrm{Xu}$, J. T., Xin, W. J., and Liu, X. G. (2007). Peri-sciatic administration of recombinant rat TNF-alpha induces mechanical allodynia via upregulation of TNF-alpha in dorsal root ganglia and in spinal dorsal horn: the role of NF-kappa B pathway. Exp. Neurol. 205, 471-484. doi: 10.1016/j.expneurol.2007.03.012

Welser-Alves, J. V., and Milner, R. (2013). Microglia are the major source of TNF-alpha and TGF-betal in postnatal glial cultures; regulation by cytokines, lipopolysaccharide, and vitronectin. Neurochem. Int. 63, 47-53. doi: 10.1016/j.neuint.2013.04.007

Weston, C., Gordon, C., Teressa, G., Hod, E., Ren, X. D., and Prives, J. (2003). Cooperative regulation by $\mathrm{Rac}$ and Rho of agrin-induced acetylcholine receptor clustering in muscle cells. J. Biol. Chem. 278, 6450-6455. doi: 10.1074/jbc.M210249200

Wheeler, D., Knapp, E., Bandaru, V. V., Wang, Y., Knorr, D., Poirier, C., et al. (2009). Tumor necrosis factor-alpha-induced neutral sphingomyelinase-2 modulates synaptic plasticity by controlling the membrane insertion of NMDA receptors. J. Neurochem. 109, 
1237-1249. doi: 10.1111/j.14714159.2009.06038.x

Willert, K., and Nusse, R. (2012). Wnt proteins. Cold Spring Harb. Perspect. Biol. 4:a007864. doi: 10.1101/cshperspect.a007864

Winberg, M. L., Mitchell, K. J., and Goodman, C. S. (1998). Genetic analysis of the mechanisms controlling target selection: complementary and combinatorial functions of netrins, semaphorins, and IgCAMs. Cell 93, 581-591. doi: 10.1016/S0092-8674(00)81187-3

Withers, G. S., Higgins, D., Charette, M., and Banker, G. (2000). Bone morphogenetic protein-7 enhances dendritic growth and receptivity to innervation in cultured hippocampal neurons. Eur. J. Neurosci. 12, 106-116. doi: 10.1046/j.14609568.2000.00889.x

Wu, H., Xiong, W. C., and Mei, L. (2010). To build a synapse: signaling pathways in neuromuscular junction assembly. Development 137, 1017-1033. doi: 10.1242/dev.038711

Xiao, L., Michalski, N., Kronander, E., Gjoni, E., Genoud, C., Knott, G., et al. (2013). BMP signaling specifies the development of a large and fast CNS synapse. Nat. Neurosci. 16, 856-864. doi: 10.1038/nn.3414

Xing, B., Bachstetter, A. D., and Van Eldik, L. J. (2011). Microglial p38alpha MAPK is critical for LPS-induced neuron degeneration, through a mechanism involving TNFalpha. Mol. Neurodegener. 6, 84. doi: 10.1186/1750-1326-6-84

$\mathrm{Xu}$, B., Goldman, J. S., Rymar, V. V., Forget, C., Lo, P. S., Bull, S. J., et al. (2010). Critical roles for the netrin receptor deleted in colorectal cancer in dopaminergic neuronal precursor migration, axon guidance, and axon arborization. Neuroscience 169, 932-949. doi: 10.1016/j.neuroscience.2010.05.025 Yetnikoff, L., Eng, C., Benning, S., and Flores, C. (2010). Netrin-1 receptor in the ventral tegmental area is required for sensitization to amphetamine. Eur. J. Neurosci. 31, 1292-1302. doi: 10.1111/j.14609568.2010.07163.x

Yetnikoff, L., Labelle-Dumais, C., and Flores, C. (2007). Regulation of netrin- 1 receptors by amphetamine in the adult brain. Neuroscience 150, 764-773. doi: 10.1016/j.neuroscience.2007.09.069

Yi, J. J., Barnes, A. P., Hand, R., Polleux, F., and Ehlers, M. D. (2010). TGF-beta signaling specifies axons during brain development. Cell 142, 144-157. doi: 10.1016/j.cell.2010.06.010

Yin, Y., Miner, J. H., and Sanes, J. R. (2002). Laminets: lamininand netrin-related genes expressed in distinct neuronal subsets. Mol. Cell. Neurosci. 19, 344-358. doi: 10.1006/mcne.2001.1089

Yu, X., and Malenka, R. C. (2003). Beta-catenin is critical for dendritic morphogenesis. Nat. Neurosci. 6, 1169-1177. doi: 10.1038/nn1132

Yu, X. M., Gutman, I., Mosca, T. J., Iram, T., Ozkan, E., Garcia, K. C., et al. (2013). Plum, an immunoglobulin superfamily protein, regulates axon pruning by facilitating TGFbeta Signaling. Neuron 78, 456-468. doi: 10.1016/j.neuron. 2013.03.004

Zakka, L. R., Fradkov, E., Keskin, D. B., Tabansky, I., Stern, J. N., and Ahmed, A. R. (2012). The role of natural killer cells in autoimmune blistering diseases. Autoimmunity 45, 44-54. doi:

$10.3109 / 08916934.2011$ 606446

Zhang, B., Luo, S., Dong, X. P., Zhang, X., Liu, C., Luo, Z., et al. (2007). Beta-catenin regulates acetylcholine receptor clustering in muscle cells through interaction with rapsyn. J. Neurosci. 27, 3968-3973. doi 10.1523/JNEUROSCI.4691-06.2007

Zhang, F., Endo, S., Cleary, L. J., Eskin, A., and Byrne, J. H. (1997). Role of transforming growth factor-beta in long-term synaptic facilitation in Aplysia. Science 275, 1318-1320. doi: $10.1126 /$ science.275.5304.1318

Zhang, H., and Dougherty, P. M. (2011). Acute inhibition of signalling phenotype of spinal GABAergic neurons by tumour necrosis factor-alpha. J. Physiol. 589, 4511-4526. doi: 10.1113/jphysiol.2011.215301

Zhang, L., Berta, T., Xu, Z. Z., Liu, T., Park, J. Y., and Ji, R. R. (2011). TNF-alpha contributes to spinal cord synaptic plasticity and inflammatory pain: distinct role of TNF receptor subtypes 1 and 2. Pain 152, 419-427. doi: 10.1016/j.pain.2010.11.014

Zhang, X., and Zhang, Y. (2012). DBL-1, a TGF-beta, is essential for Caenorhabditis elegans aversive olfactory learning. Proc. Natl. Acad. Sci. U.S.A. 109, 17081-17086. doi: 10.1073/pnas.1205982109

Zheng, F., Adelsberger, H., Muller, M. R., Fritschy, J. M., Werner, S., and Alzheimer, C. (2009). Activin tunes GABAergic neurotransmission and modulates anxiety-like behavior. Mol. Psychiatry 14, 332-346. doi: 10.1038/sj.mp.4002131

Zhong, Y., Zhou, L. J., Ren, W. J., Xin, W. J., Li, Y. Y., Zhang, T., et al. (2010). The direction of synaptic plasticity mediated by $\mathrm{C}$-fibers in spinal dorsal horn is decided by Src-family kinases in microglia: the role of tumor necrosis factor-alpha. Brain Behav. Immun. 24, 874-880. doi: 10.1016/j.bbi.2010.01.007

Zhou, Y. X., Zhao, M., Li, D., Shimazu, K., Sakata, K., Deng, C. X., et al. (2003). Cerebellar deficits and hyperactivity in mice lacking Smad4. J. Biol. Chem. 278, 42313-42320. doi: 10.1074/jbc.M308287200

Ziel, J. W., and Sherwood, D. R. (2010). Roles for netrin signaling outside of axon guidance: a view from the worm. Dev. Dyn. 239, 1296-1305. doi: $10.1002 /$ dvdy.22225

Conflict of Interest Statement: The authors declare that the research was conducted in the absence of any commercial or financial relationships that could be construed as a potential conflict of interest.

Received: 02 July 2013; accepted: 29 August 2013; published online: 18 September 2013.

Citation: Poon VY, Choi $S$ and Park M (2013) Growth factors in synaptic function. Front. Synaptic Neurosci. 5:6. doi: 10.3389/fnsyn.2013.00006

This article was submitted to the journal Frontiers in Synaptic Neuroscience.

Copyright (c) 2013 Poon, Choi and Park. This is an open-access article distributed under the terms of the Creative Commons Attribution License (CC BY). The use, distribution or reproduction in other forums is permitted, provided the original author(s) or licensor are credited and that the original publication in this journal is cited, in accordance with accepted academic practice. No use, distribution or reproduction is permitted which does not comply with these terms. 